\title{
Synthesis and Mechanism of Formation of Oxadeazaflavines by Microwave Thermal Cyclization of ortho-Halobenzylidene Barbiturates
}

\author{
J. Daniel Figueroa-Villar*a and Sandra C. G. de Oliveira \\ Grupo de Química Medicinal, Departamento de Química, Instituto Militar de Engenharia, \\ Praça General Tibúrcio 80, Praia Vermelha, 22290-270 Rio de Janeiro-RJ, Brazil
}

\begin{abstract}
A reação de ciclização térmica de $o$-halobenzilideno barbituratos foi desenvolvida como um simples e eficiente método para a preparação de oxadeazaflavinas. A utilização de condições de reação em estado sólido com irradiação de microondas forneceu os produtos em 5 min e com rendimentos entre 47 e $98 \%$. Os resultados experimentais das sínteses e a análise termogravimétrica das reações concordam com os resultados da simulação do mecanismo por modelagem molecular, indicando que a reação ocorre através de uma ciclização hetero-Diels-Alder intra-molecular, seguida por um processo rápido de re-aromatização.
\end{abstract}

The thermal cyclization reaction of $o$-halobenzylidene barbiturates was developed as an efficient and simple method for the preparation of oxadeazaflavines. The use of solid state reaction conditions with microwave irradiation afforded the products in 5 min with 47 to $98 \%$ yield. Experimental synthetic results and thermogravimetric reaction analyses agree with the molecular modeling mechanism simulation, indicating that this reaction occurs through an intramolecular hetero-Diels-Alder cyclization followed by fast re-aromatization.

Keywords: oxadeazaflavines, $o$-halobenzylidene barbiturates, microwave irradiation, intramolecular hetero-Diels-Alder

\section{Introduction}

Oxadeazaflavines (2H-chromeno[2,3-d]pyrimidine2,4-(3H)-diones or 10-oxa-5-deazaflavines) are interesting compounds with great potential as intermediates for the synthesis of new heterocyclic systems ${ }^{1-8}$ and as selective organic oxidants under mild conditions. ${ }^{3}$ Also, derivatives and analogues of oxadeazaflavines display important bioactivity, being potential drugs. ${ }^{9-12}$ For many years, several chemists tried without success to prepare the simplest oxadeazaflavine by the direct reaction of barbituric acid with salicylaldehyde, ${ }^{13-15}$ thus making necessary the use of more complex synthetic procedures to obtain the desired products. ${ }^{1-3}$ In the beginning of the 1990 decade there were reported two new simple and complementary methods for the preparation of oxadeazaflavines from barbituric acid. ${ }^{16,17}$ The first method uses the condensation reaction of salicylaldehyde and analogues with barbituric acid at room temperature to yield an orange oxonium salt that affords oxadeazaflavines under dehydrating conditions, ${ }^{16}$ as shown in Scheme 1. Unfortunately, this method only functions well with salicylaldehydes without effective electron-withdrawing groups at the aromatic ring.

The second method, which is based on the thermal cyclization of $o$-halobenzylidene barbiturates, can be applied with success to starting materials containing electron-withdrawing and electron-donating groups at the aromatic ring. ${ }^{17}$ The draw of this last method is the need

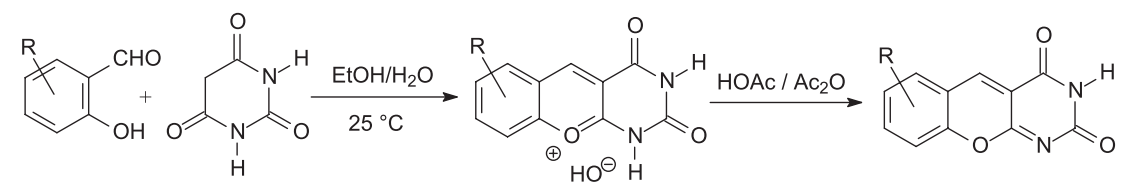

Scheme 1. Synthesis of oxadeazaflavines from salicylaldehyde and barbituric acid. ${ }^{16}$ 
for relatively long reaction times at high temperatures, for example 1.5 hours at $260{ }^{\circ} \mathrm{C}$, affording oxadeazaflavines in medium to low yields ( $50 \%$ or lower). On the other hand, because benzylidene barbiturates are easy to prepare by reaction of benzaldehydes with barbituric acid ${ }^{17-20}$ and have been used as starting materials for different reactions, ${ }^{21-28}$ the optimization of the second reaction method is important.

One important procedure to improve reactions and decrease their environmental impact is the exclusion of solvents in combination with the use of microwave irradiation. ${ }^{29-35}$ The use of microwaves has an important effect to improve yields and reduce reaction times. ${ }^{36-40}$

In this work, we have used solvent-free microwave irradiation for the very efficient solid state synthesis of oxadeazaflavines from $o$-halobenzylidene barbiturates. The simulation results of the reaction mechanism by molecular modeling, which combine with the synthesis results and the thermogravimetric analysis, indicate that this reaction occurs through an intermolecular hetero-Diels-Alder reaction.

\section{Results and Discussion}

In order to determine if the conversion of $o$-haloaryl barbiturylidenes to oxadeazaflavines could be carried out with success using microwaves as the activation energy source, we conducted the cyclization reaction of the benzylidene from 6-bromopiperonal under conventional and microwave heating conditions, as shown in Scheme 2.

As a first result it was found that the reaction time with microwave irradiation without solvent was $60 \mathrm{~min}$, affording compound $\mathbf{2}$ in $95 \%$ yield. On the other hand, the conventional heating procedure required the use of Dowtherm-A as solvent and a reaction time of $60 \mathrm{~min}$ at $260{ }^{\circ} \mathrm{C}$, affording only $50 \%$ yield. If the reaction with conventional heating was maintained for longer times there was decomposition of product $\mathbf{2}$.
In order to decrease the reaction time with microwave irradiation we proceeded to test the reaction in the presence of sodium chloride as a solid heat dispersion agent. The reaction was tested using a 2:1 mixture of the starting material (1) with $\mathrm{NaCl}$. Under those conditions it was found that the use of $\mathrm{NaCl}$ as heat dispersing media lead to $98 \%$ yield of $\mathbf{2}$ in only $5 \mathrm{~min}$ of reaction time.

With these results in hand we decided to study the effect of the halogen atom on the reaction. Therefore, the thermal cyclization reaction was carried out using the benzylidenes from of 2-fluorobenzaldehyde (3), 2-chlorobenzaldehyde (4) and 2-bromobenzaldehyde (5). For these compounds, the cyclization reaction was first carried out in a thermal balance (TGA) without $\mathrm{NaCl}$, to determine the reaction temperature and the lost of mass. In order to determine the reaction times and yields, the same three reactions were carried out using microwave irradiation without $\mathrm{NaCl}$. Interestingly, when the reaction with microwaves was carried out with the starting materials 3, $\mathbf{4}$ and 5, the yield without the presence of $\mathrm{NaCl}$ was 88,81 and $47 \%$, respectively. However, when the reaction was executed with $\mathrm{NaCl}$ the yields were very similar $(97-99 \%)$. The data for the thermo gravimetric and the microwave assisted reactions without $\mathrm{NaCl}$ is summarized in Table 1.

The data from Table 1 indicates that, as expected, the mass loss for each reaction agrees with the emission of an $\mathrm{HX}$ molecule $(\mathrm{X}=\mathrm{F}, \mathrm{Cl}$ and $\mathrm{Br})$. The comparison of the results with the different halogenated starting materials suggests that a higher electronegativity and smaller atomic size favors the reaction. For example, it can be observed that the cyclization reaction occurs at lower temperature for the fluorinated benzylidene barbiturate $3\left(198{ }^{\circ} \mathrm{C}\right)$, and at higher temperatures for the brominated analogue 5 $\left(227{ }^{\circ} \mathrm{C}\right)$, indicating that the greater electronegativity and smaller size of fluorine favors the reaction. When comparing the reaction results of the bromo and chlorobenzylidene barbiturates is interesting to notice that it occurs at about the

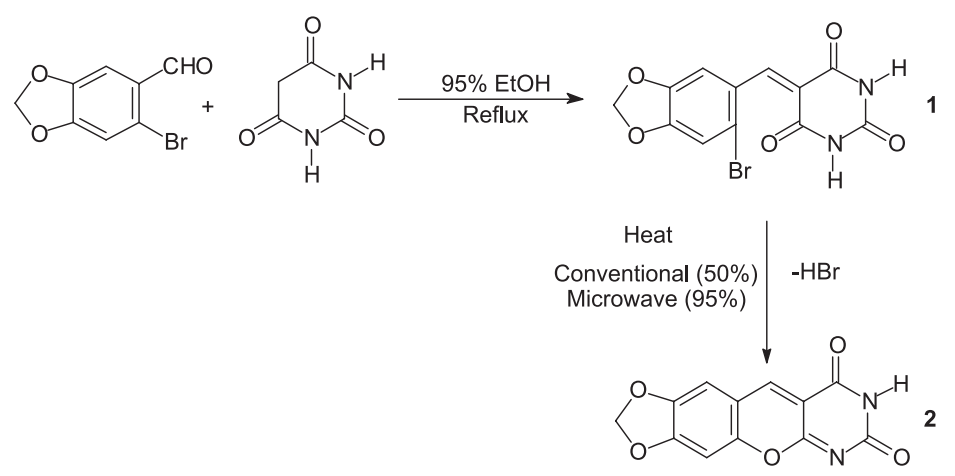

Scheme 2. Thermal cyclization of the 6-bromopiperonylidene barbiturate (1) to produce $2 \mathrm{H}-[1,3]$ dioxolo[4', $\left.5^{\prime}: 6,7\right]$ chromeno[2,3-d]pyrimidine-2,4(3H)dione (2) . 
Table 1. Yields, reaction times and reaction temperatures for the thermal cyclization of the ortho-halobenzylidene barbiturates $\mathbf{3}, \mathbf{4}$ and $\mathbf{5}$

\begin{tabular}{|c|c|c|c|c|c|}
\hline Compound & $\begin{array}{c}\text { Reaction } \\
\text { time }^{c} / \min \end{array}$ & $\begin{array}{c}\text { Reaction } \\
\text { Temperature }{ }^{\mathrm{b}} /\left({ }^{\circ} \mathrm{C}\right)\end{array}$ & $\begin{array}{c}\text { Calculated } \\
\text { mass loss / }(\%)\end{array}$ & $\begin{array}{c}\text { Experimental } \\
\text { mass loss } /(\%)\end{array}$ & $\begin{array}{c}\text { Yield }^{\mathrm{c}} / \\
(\%)\end{array}$ \\
\hline 3 & 30 & 198 & 8.55 & 8.70 & 88 \\
\hline 4 & 30 & 228 & 14.57 & 15.65 & 81 \\
\hline 5 & 40 & 227 & 27.43 & 31.50 & 47 \\
\hline
\end{tabular}

${ }^{\mathrm{b}}$ Data obtained from the reactions by thermogravimetric monitoring. ${ }^{\mathrm{D}}$ Data obtained from the microwave-assisted reactions.

same temperature for both compounds (228 and $227^{\circ} \mathrm{C}$ ). However, the reaction occurs faster for the chlorinated compound 4 (30 $\mathrm{min}$ ) affording $81 \%$ yield, while the reaction for the brominated compound 5 is slower $(40 \mathrm{~min}$ ) and gives a lower yield $(47 \%)$.

In solution, $\mathrm{Br}^{-}$is considered a better leaving group than $\mathrm{Cl}^{-}$or $\mathrm{F}^{-}$, but this could not be the case for the reaction without solvent. Also, the synthesis results suggest that the best leaving group nature of bromide is not an important factor for the reaction, being evident that a greater atom size may cause steric hindrance for the first step of the cyclization reaction.

Based on these results we proposed the reaction mechanism shown in Scheme 3, which is a very logical possibility. The first mechanism step would be an intramolecular hetero-Diels-Alder cyclization, leading to the first transition state (TS1), with loss of aromaticity on the benzylidene ring, leading to the reaction intermediate (INT1). The second reaction step would be the conversion of INT1 to the oxadeazaflavine (6) by the loss of the HX molecule through the second transition state (TS2). The activation energy for the first step (Ea1) corresponds to the energy difference between the reagent and TS1. For the second reaction step the activation energy (Ea2) corresponds to the energy difference between INT1 and TS2. It is worth mentioning that the product energy corresponds to the addition of the energies of $\mathrm{HX}$ and compound $\mathbf{6}$. Because the loss of aromaticity the first step of the proposed mechanism, which is the initial electrocyclic $\mathrm{C}-\mathrm{O}$ bond formation, is the rate determining step of the whole process. Therefore, the activation energy for this initial step should be the activation energy for the whole reaction. Also, in this first step, the presence of the bulkier and less electronegative bromine atom would be unfavorable, due to the steric effect, while the presence of the small and more electronegative fluorine atom would be favorable.

In order to correlate the experimental data with the proposed reaction mechanism we carried out a molecular modeling study to determine the activation energy of each proposed step. For this, we calculated the energy of the starting materials $(\mathbf{3}, \mathbf{4}$ and $\mathbf{5})$, the transition states (TS1 and TS2), the intermediate (INT1) and the products ( 6 and $\mathrm{HX})$. Because of the solid state nature of the reaction, all the calculations were conducted in vacuum. All the calculations were carried out using the B3LYP method with the 6-31G* basis set with the Spartan06 program, and the results are shown in Table 2.

The results from Table 2 show that the activation energies for the 2-bromo derivative (5) and the 2-chloro derivative (4) are very similar, 42.41 and $39.21 \mathrm{kcal} \mathrm{mol}^{-1}$, respectively, being about $10 \mathrm{kcal} \mathrm{mol}^{-1}$ higher than the activation energy for the fluorine derivative (3). These results are in agreement with the experimental data, which shows that the reaction temperature for compound $\mathbf{3}$ is $30^{\circ} \mathrm{C}$ lower than for compounds $\mathbf{4}$ and $\mathbf{5}$, which reactions occur at about the same temperature, $228{ }^{\circ} \mathrm{C}$ and $227^{\circ} \mathrm{C}$, respectively. Also, the slower reaction time and lower yield for the brominated substrate may be partially explained by its activation energy being $3.2 \mathrm{kcal} \mathrm{mol}^{-1}$ higher than that for the chlorinated

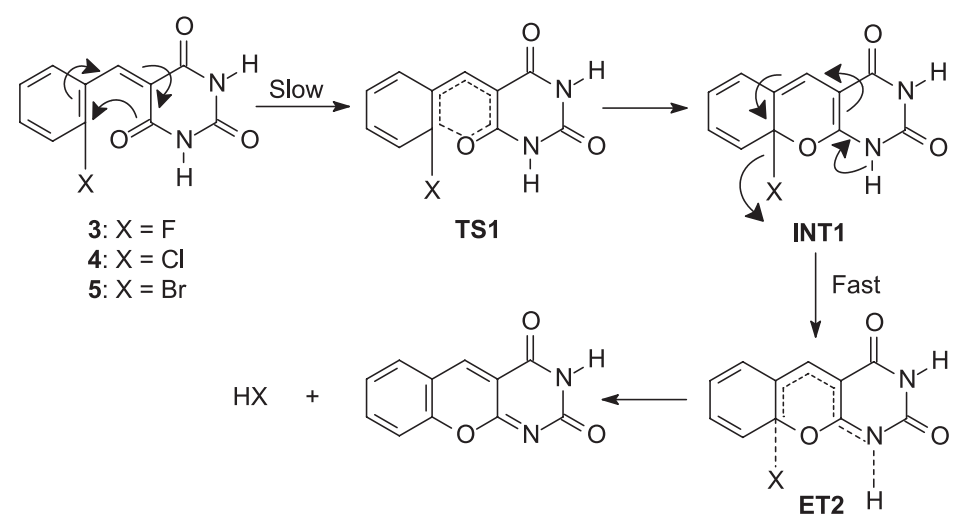

Scheme 3. Proposed mechanism for the thermal cyclization reaction of $o$-halobenzylidene barbiturates. 
Table 2. Calculated (B3LYP 6-31G*) energies for the reagents $(\mathbf{3}, \mathbf{4}$ and $\mathbf{5}$ ), transition states (TS1 and TS2) and intermediate (INT1) of the proposed reaction mechanism

\begin{tabular}{lccccccc}
\hline \multirow{2}{*}{ Halogen } & \multicolumn{9}{c}{ Energy / $\left(\mathrm{kcal} \mathrm{\text {mol } ^ { - 1 } )}\right.$} \\
\cline { 2 - 8 } & Reagent & TS1 & AE1 & INT1 & TS2 & Product & AE2 \\
\hline $\mathrm{F}$ & -99.96 & -69.85 & 29.81 & -80.68 & -69.84 & -91.11 & 10.84 \\
$\mathrm{Cl}$ & -61.38 & -22.17 & 39.21 & -22.17 & -22.16 & -43.45 & 0.01 \\
$\mathrm{Br}$ & -49.05 & -6.64 & 42.41 & -21.69 & -21.69 & -29.34 & 0.00 \\
\hline
\end{tabular}

${ }^{\mathrm{d}}$ Sum of the energy of $\mathbf{6}$ and HX.

benzylidene barbiturate. Since the activation energy difference for the reagents $\mathbf{4}$ and $\mathbf{5}$ is so small, other effects should be involved to describe their reaction difference. Interestingly, the second activation energy (Ea2), which is much lower for all the reactions, is zero for $\mathbf{4}$ and $\mathbf{5}$, indicating that in these two cases does not exist a second transition state. The graphic of correlation between the relative energy and the reaction coordinate for reaction mechanism the fluorinated reagent $(\mathbf{3})$ is shown in Scheme 4, making clear that in the case of this reagent exists an intermediate (INT1) and two transition states (TS1 and TS2), different from the brominated and chlorinated reagents $\mathbf{4}$ and $\mathbf{5}$.

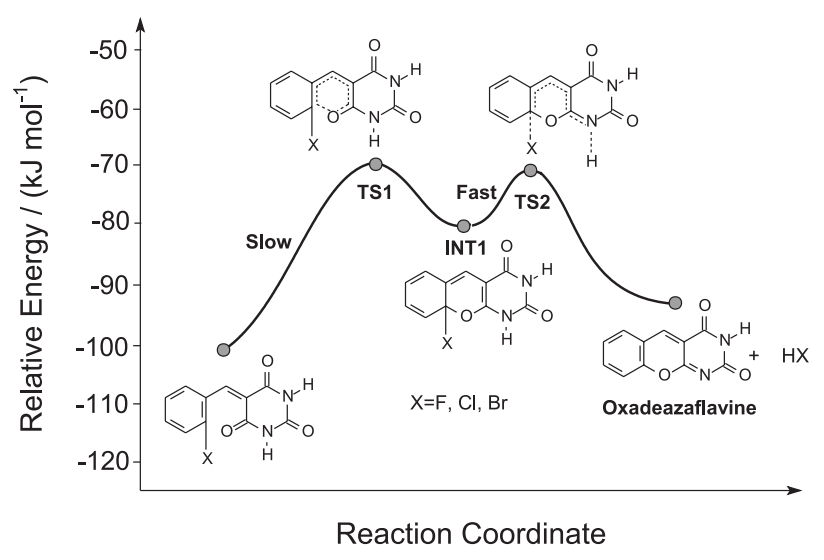

Scheme 4. Graphic of relative energy vs reaction coordinate for the mechanism of formation of oxadeazaflavine from the fluorinated reagent (3).

\section{Conclusions}

Our results indicate that oxadeazaflavines can be most conveniently obtained by the solid state thermal cyclization of orto-halobenzylidene barbiturates using microwave irradiation without any solvent and with the presence of $\mathrm{NaCl}$. This methodology leads to much better yields (usually above 95\%) and shorter reaction times, than for the conventionally heating reaction. It was observed that the reaction times can be significantly decreased and the yields increased when $\mathrm{NaCl}$ is used as a heat dispersion agent mixed with the starting material, the orto-halobenzylidene barbiturates. The starting materials are easily obtained by Knovenagel condensation of barbituric acid and the desired $o$-halobenzaldehyde, in yields normally greater than $90 \%$, thus leading to overall yields above $85 \%$. Since this methodology can be applied to any type of $o$-halobenzaldehyde, we believe that this is the most convenient reported route to prepare oxadeazaflavines.

The experimental data obtained from the thermogravimetric monitoration of the thermal reactions agree with the reaction activating energies calculated by molecular modeling, suggesting that this reaction occurs first through a rate-determining intramolecular heteronuclear Diels-Alder-type cyclization, followed by re-aromatization by elimination of $\mathrm{HX}(\mathrm{X}=\mathrm{F}, \mathrm{Cl}, \mathrm{Br})$ to yield the oxadeazaflavine.

The efficiency of this reaction in terms of high yields, short reaction times and its green chemistry nature is of significant importance, especially on the application of oxadeazaflavines as starting materials for preparation of new heterocyclic compounds with different applications. Our actual focus on oxadeazaflavines is their potential applications in medicinal chemistry and as starting materials in organic synthesis. For example, oxadeazaflavines could be used as strong Michael acceptors, as was conducted for the addition of barbituric acid to produce 5-(2,4,6-trioxo-hexahydropyrimidin-5-yl)$1 H$-chromeno[2,3- $d$ ] pyrimidine-2,4(3H,5H)-dione, ${ }^{21}$ which is used as anion for the preparation of $\mathrm{Zn}$ (II) complexes as water clusters. ${ }^{41}$ Also, some oxadeazaflavines are sirtuin inhibitors, an important activity against aging, apoptosis and transgenic nematodes, ${ }^{42}$ as well as effect against cancer cells. ${ }^{43}$ These compounds could also be used to prepare analogues of 2-deoxo-phenyl-5-deazaflavines, which are a new class of antitumor agents. ${ }^{44}$ Because oxadeazaflavines are easily reduced by oxidation of some alcohols, ${ }^{45}$ another actual interests in this type of compounds is their use as specific selective oxidants.

\section{Experimental}

\section{General}

All reagents were purchased from Sigma-Aldrich Chemical Company and were used without any previous purification. All the solvents were purchased from Merck 
and were distilled before being used. The thin layer chromatographic analyses were carried out using Merck precoated silica gel plates on aluminum. Melting points were measured in a Fisher-Jones apparatus and are uncorrected.

\section{Spectroscopy measurements}

The NMR spectra were determined in a Varian UNITY-300 spectrometer operating at $300 \mathrm{MHz}$ for hydrogen and $75 \mathrm{MHz}$ for carbon. All the samples were run in $5 \mathrm{~mm}$ NMR tubes using DMSO- $d_{6}$ as solvent and TMS as internal standard. The IR spectra were recorded in a Perkin-Elmer 1710 FTIR spectrometer using samples at $1 \%$ in $\mathrm{KBr}$ pellets.

\section{Thermogravimetric analysis}

The thermogravimetric monitoring of the thermal reaction was conducted using $5.0 \mathrm{mg}$ of each starting material (compounds $\mathbf{3}, \mathbf{4}$ and $\mathbf{5}$ ) in a thermogravimetric analyzer Shimadzu TGA-50.

\section{Molecular modeling}

The molecular modeling calculations were carried out in a computer with an Intel dual $2.66 \mathrm{GHz}$ processor with 2048 Mb RAM using the Spartan06 package. The calculations were performed using the functional density (DFT) B3LYP method with the 6-31G* basis set. A similar procedure was used with the transition state module of the Spartan06 package, which was used for the transition state geometry optimization and energy calculations. For the proposed transition state calculations it was also included the calculation of the infrared spectrum, in order to guarantee, with the presence of a single imaginary vibration mode, the transition state nature of the entity.

\section{General procedure for the preparation of the benzylidene barbiturates $\mathbf{1}, \mathbf{2}$ and $\mathbf{3}$}

A solution of $0.128 \mathrm{~g}$ (10 mmol) of barbituric acid in $20 \mathrm{~mL}$ of $95 \%$ ethanol was mixed with $1.1 \mathrm{mmol}$ of the desired aldehyde dissolved in $10 \mathrm{~mL}$ of the same solvent. The mixture was kept under reflux for $1 \mathrm{~h}$. After cooling to room temperature, the reaction mixture was filtered by suction and the solid product recrystallized from $95 \%$ ethanol.

\section{Synthesis of o-bromopiperonylidene barbiturate (1)}

Compound 1 was prepared according to the described general procedure using $2.29 \mathrm{~g}(10 \mathrm{mmol})$ of bromopiperonal.
Compound 1 was obtained as yellow-orange solid in $96 \%$ yield; $\mathrm{mp} 260{ }^{\circ} \mathrm{C}$ (dec.); IR ( $\mathrm{KBr}$ pellet) $\mathrm{v}_{\max } / \mathrm{cm}^{-1}: 3426$, 3198, 3084, 1754, 1700, 1684, 1581, 1488, 1430, 1383 , 1327, 1265, 1130, 1036, 934, 837, 505, and 420. ${ }^{1} \mathrm{H}$ NMR (98\% DMSO- $\left.d_{6}, 300 \mathrm{MHz}\right) \delta(\mathrm{ppm}) 11.36(\mathrm{~s}, 1 \mathrm{H}), 11.18$ $(\mathrm{s}, 1 \mathrm{H}), 8.24(\mathrm{~s}, 1 \mathrm{H}), 7.56(\mathrm{~s}, 1 \mathrm{H}), 7.34(\mathrm{~s}, 1 \mathrm{H})$ and $6.15(\mathrm{~s}$, $2 \mathrm{H}) .{ }^{13} \mathrm{C}$ NMR (98\% DMSO- $\left.d_{6}, 75 \mathrm{MHz}\right) \delta$ (ppm) 162.9, 161.1, 152.0, 150.9, 150.0, 146.2, 126.2, 119.3, 118.7, 112.1, 111.9 and 102.7.

Synthesis of 2H-[1,3]dioxolo[4',5':6,7]chromeno[2,3-d] pyrimidine-2,4(3H)-dione (2) by conventional heating

$1.0 \mathrm{~g}(2.9 \mathrm{mmol})$ of $o$-bromopiperonylidene barbiturate (1) was dissolved in $50 \mathrm{~mL}$ of Dowtherm-A and heated at $260{ }^{\circ} \mathrm{C}$ for $1 \mathrm{~h}$. After filtration of the reaction mixture the solid product was washed with petroleum ether and recrystallized from acetic acid yielding $\mathbf{2}$ as a brown solid, $0.38 \mathrm{~g}$ (50\% yield); $\mathrm{mp}>390^{\circ} \mathrm{C}$; IR (KBr pellet) $v_{\max } / \mathrm{cm}^{-1}$. 3171, 3051, 2832, 1700, 1678, 1632, 1608, 1561, 1487, 1456, 1403, 1285, 1251, 1128, 1070, 852, 767, 540, 508 and $441 .{ }^{1} \mathrm{H}$ NMR (98\% DMSO- $\left.d_{6}, 300 \mathrm{MHz}\right) \delta(\mathrm{ppm})$ $11.30(\mathrm{~s}, 1 \mathrm{H}), 8.81(\mathrm{~s}, 1 \mathrm{H}), 7.54(\mathrm{~s}, 1 \mathrm{H}), 7.49(\mathrm{~s}, 1 \mathrm{H})$ and $6.31(\mathrm{~s}, 2 \mathrm{H}) .{ }^{13} \mathrm{C}$ NMR (98\% DMSO- $\left.d_{6}, 75 \mathrm{MHz}\right) \delta(\mathrm{ppm})$ $164.5,162.7,159.8,154.2,150.3,149.5,140.9,112.4$, $112.2,110.4,102.3$ and 96.7. LREIMS $e / z$ (int.) 258.00 (100), 215.05 (65), 187.05 (55), 149.03 (57), 135.12 (4), 123.11 (6), 109.10 (9), 97.10 (15), 83.08 (20), 69.06 (37) and 57.04 (47).

Synthesis of 2H-[1,3]dioxolo[4',5':6,7]chromeno[2,3-d] pyrimidine-2,4(3H)-dione (2) by microwave heating without $\mathrm{NaCl}$

$0.10 \mathrm{~g}(0.29 \mathrm{mmol})$ of $\mathbf{1}$ was set in a glass vial connected with a bubbling flask containing a saturated solution of $\mathrm{NaHCO}_{3}$ in a commercial microwave oven. The flask was heated with microwaves $(1100 \mathrm{~W})$ for $5 \mathrm{~min}$ in a Discover 1 (CEM) reactor. The reaction was repeated using microwave heating times of 10, 20, 30, 40, 50,60, 70 and $80 \mathrm{~min}$. The solid reaction mixtures were washed with a 10:1 ethanol:DMSO mixture $(1 \mathrm{~mL})$ and then with pure ethanol $(2 \times 1 \mathrm{~mL})$ to yield pure $\mathbf{2}$ as a mustard solid. The best result (95\% yield) was obtained in $60 \mathrm{~min}$ of microwave irradiation.

Synthesis of 2H-[1,3]dioxolo[4',5':6,7]chromeno[2,3-d] pyrimidine-2,4(3H)-dione (2) by microwave heating with $\mathrm{NaCl}$

The same procedure as before was carried out but using a mixture of $0.10 \mathrm{~g}(0.29 \mathrm{mmol})$ of 1 grounded with $0.2 \mathrm{~g}$ of $\mathrm{NaCl}$ and heating for $5 \mathrm{~min}$. In this case, pure 2 was obtained after dissolving the reaction mixture in hot ethyl 
acetate, filtering out the sodium chloride and cooling the filtrate to yield crystals of pure $\mathbf{2}$ in $98 \%$ yield.

\section{Synthesis of o-fluorobenzylidene barbiturate (3)}

Compound $\mathbf{3}$ was prepared according to the described general procedure, using $0.136 \mathrm{~g}(1.1 \mathrm{mmol})$ of $o$-fluorobenzaldehyde. Compound $\mathbf{3}$ was obtained as yellow crystals in $82 \%$ yield; $\mathrm{mp} 270-272^{\circ} \mathrm{C} ; \mathrm{IR}(\mathrm{KBrpellet}) \nu_{\max } / \mathrm{cm}^{-1}$ : 3438, 2835, 1728, 1683, 1603, 1438 and 1320. ${ }^{1} \mathrm{H}$ NMR (98\% DMSO- $\left.d_{6}, 300 \mathrm{MHz}\right) \delta(\mathrm{ppm}) 7.24(\mathrm{dd}, 1 \mathrm{H}, J 1.5$ and $7.3 \mathrm{~Hz}), 7.30(\mathrm{dd}, 1 \mathrm{H}, J 1.8$ and $7.5 \mathrm{~Hz}), 7.54(\mathrm{~d}, 1 \mathrm{H}$, $J 8.1 \mathrm{~Hz}), 7.94(\mathrm{~d}, 1 \mathrm{H}, J 5.7 \mathrm{~Hz}), 8.28(\mathrm{~s}, 1 \mathrm{H}), 11.30(\mathrm{~s}$, $1 \mathrm{H})$ and $11.48(\mathrm{~s}, 1 \mathrm{H}) .{ }^{13} \mathrm{C}$ NMR (DMSO- $\left.d_{6}, 300 \mathrm{MHz}\right)$ $\delta$ (ppm) 115.4, 121.4, 121.6, 123.9, 132.3, 133.7, 145.8, $150.3,160.7,161.1$ and 162.8 .

\section{Synthesis of o-chlorobenzylidene barbiturate (4)}

Compound $\mathbf{4}$ was prepared according to the described general procedure, using $0.155 \mathrm{~g}(1.1 \mathrm{mmol})$ of $o$-chlorobenzaldehyde, and was obtained as yellow crystals in $81 \%$ yield; mp $214-216{ }^{\circ} \mathrm{C}$; IR ( $\mathrm{KBr}$ pellet) $v_{\max } / \mathrm{cm}^{-1}$ : 3441, 2836, 1754, 1693, 1597, 1433, 1322. ${ }^{1} \mathrm{H}$ NMR (DMSO- $\left.d_{6}, 300 \mathrm{MHz}\right) \delta(\mathrm{ppm}) 7.36(\mathrm{t}, 1 \mathrm{H}, J 6.0 \mathrm{~Hz}), 7.45$ (dd, $1 \mathrm{H}, J 6.0 \mathrm{~Hz}), 7.53$ (d, 1H, J 6.0 Hz), 7.75 (d, 1H, J6.0 $\mathrm{Hz}), 8.30(\mathrm{~s}, 1 \mathrm{H}), 11.29(\mathrm{~s}, 1 \mathrm{H})$ and $11.52(\mathrm{~s}, 1 \mathrm{H}) .{ }^{13} \mathrm{C} \mathrm{NMR}$ (DMSO- $\left.d_{6}, 300 \mathrm{MHz}\right) \delta$ (ppm) 121.8, 126.4, 129.0, 132.0, $132.1,132.3,133.3,150.0,150.3,161.0$ and $162.73 \mathrm{ppm}$.

\section{Synthesis of o-bromobenzylidene barbiturate (5)}

Compound 5 was prepared according to the described general procedure, using $0.203 \mathrm{~g}(1.1 \mathrm{mmol})$ of $o$-bromobenzaldehyde, and was obtained as yellow crystals in $86 \%$ yield; $\mathrm{mp} 220-223{ }^{\circ} \mathrm{C}$; IR (KBr pellet) $v_{\max } / \mathrm{cm}^{-1}$ : $3440,2845,1730,1691,1601,1431$ and $1321 \mathrm{~cm}^{-1}$. ${ }^{1} \mathrm{H}$ NMR (DMSO- $\left.d_{6}, 300 \mathrm{MHz}\right) \delta(\mathrm{ppm}) 7.36(\mathrm{dd}, 1 \mathrm{H}, J 8.0$ and $9.0 \mathrm{~Hz}), 7.39(\mathrm{dd}, 1 \mathrm{H}, J 8.0$ and $9.0 \mathrm{~Hz}), 7.68(\mathrm{~d}, 1 \mathrm{H}$, $J 8.0 \mathrm{~Hz}), 7.71(\mathrm{~d}, 1 \mathrm{H}, J 9.0 \mathrm{~Hz}), 8.22(\mathrm{~s}, 1 \mathrm{H}), 11.28(\mathrm{~s}$, $1 \mathrm{H}), 11.50 \mathrm{ppm}(\mathrm{s}, 1 \mathrm{H}) \cdot{ }^{13} \mathrm{C}$ NMR (DMSO- $d_{6}, 300 \mathrm{MHz}$ ) $\delta$ (ppm) 121.4, 123.4, 126.9, 132.0, 132.1, 134.2, 150.3, 152.0, 161.0 and $162.7 \mathrm{ppm}$.

Procedure for the preparation of the $2 H$-chromeno[2,3-d] pyrimidine-2,4(3H)-diones (oxadeazaflavine) with microwave heating

The $o$-haloaryl barbiturylydenes $\mathbf{1}, \mathbf{2}$ and $\mathbf{3}(0.3 \mathrm{mmol})$ were placed in a flat bottom flask connected to a glass tube submerged in a saturated sodium bicarbonate solution to capture the acid produced by the reaction. The flask was set inside a commercial microwave reactor Discover 1 $(\mathrm{CEM})$ and irradiated at $1100 \mathrm{~W}$ for consecutive periods of $10 \mathrm{~min}$. A sample of the reaction mixture was analyzed by thin layer chromatography after every $10 \mathrm{~min}$ of reaction until observing the complete disappearance of the starting material. The solid reaction residue was then washed with a 10:1 ethanol:DMSO mixture. Product 6 was obtained as an amorphous light brown solid with a melting point of $325-328{ }^{\circ} \mathrm{C}$ in 47 to $88 \%$ yield. IR ( $\mathrm{KBr}$ pellet) $v_{\max } / \mathrm{cm}^{-1}: 3439,2833,1682,1636,1608,1458$ and 1321. ${ }^{1} \mathrm{H}$ NMR (DMSO- $\left.d_{6}, 300 \mathrm{MHz}\right) \delta(\mathrm{ppm}) 7.92-7.86(\mathrm{~m}$, $2 \mathrm{H}), 8.27-8.19(\mathrm{~m}, 2 \mathrm{H}), 9.69(\mathrm{~s}, 1 \mathrm{H})$ and $11.50(\mathrm{~s}, 1 \mathrm{H})$. ${ }^{13} \mathrm{C}$ NMR (DMSO- $\left.d_{6}, 75 \mathrm{MHz}\right) \delta$ (ppm) 163.7, 158.0, 157.21, 153.6, 147.0, 142.7, 132.7, 130.1, 120.3, 117.4 and 108.7. Elemental analysis: calc. for $\mathrm{C}_{11} \mathrm{H}_{6} \mathrm{O}_{3} \mathrm{~N}_{2}: \mathrm{C} 61.68, \mathrm{H}$ 2.80, N 13.08; found: C 61.03, H 2.69, N 13.06.

Procedure for the preparation of the $2 \mathrm{H}$-chromeno[2,3-d] pyrimidine-2,4(3H)-diones (oxadeazaflavine) with microwave heating using sodium chloride

It was used the same procedure described for the preparation of the oxadeazaflavine, but mixing the starting material $(0.3 \mathrm{mmol})$ with $0.2 \mathrm{~g}$ of $\mathrm{NaCl}$. In this case the reaction mixture was monitored by thin layer chromatography every $1.0 \mathrm{~min}$ of microwave heating $(1100 \mathrm{~W})$ until all the starting material disappeared. The best reaction time for the three starting materials was $5 \mathrm{~min}$. The reaction mixture was dissolved in $50 \mathrm{~mL}$ of hot ethylacetate, filtered to eliminate the $\mathrm{NaCl}$ and the filtrate was concentrated to dryness under vacuum to afford pure $\mathbf{6}$ as an amorphous light brown solid. The yields for all cases varied from 97 to $99 \%$.

\section{Supplementary Information}

Supplementary information (Figures S1-S21) is available free of charge at http://jbcs.sbq.org.br as a PDF file.

\section{Acknowledgments}

The authors are grateful to Coordenação de Pesquisa e Estudos Superiores (CAPES-Pródefesa), Conselho Nacional de Desenvolvimento Científico e Tecnológico (CNPq), and Fundação Carlos Chagas Filho de Amparo à Pesquisa do Estado de Rio de Janeiro (FAPERJ) and Instituto Nacional de Biologia Estrutural e Bioimagem (IMBEB) for their financial support.

\section{References}

1. Blythin, D. J.; Domalski, M. S.; Kim, Y. C.; Kuo, J; Lau, J. H.; Heterocycles 1981, 16, 203. 
2. Yoneda, F; Hirayama, R.; Yamashita, M.; Chem. Lett. 1980 , 1157.

3. Yoneda, F; Hirayama, R.; Yamashita, M.; J. Heterocycl. Chem. 1982, 19, 301.

4. Chen, X.; Tanaka, K.; Yoneda, F.; Chem. Pharm. Bull. 1990, 38, 307.

5. Kawamoto, T.; Ikeuchi, Y.; Mikata, Y.; Kishigami, M.; Yano, S.; Murayama, C.; Mori, T.; Yoneda, F.; Bioorg. Med. Chem. Lett. 2001, 11, 1745.

6. Ikeuchi, Y.; Sumiya, M.; Kawamoto, T.; Akimoto, N.; Mikata, Y.; Kishigami, M.; Yano, S.; Sasaki, T.; Yoneda, F.; Bioorg. Med. Chem. 2000, 8, 2027.

7. Chen, X.; Nagata, M.; Tanaka, K.; Yoneda, F.; J. Chem. Soc. Chem. Commun. 1989, 44.

8. Kammoun, M.; Turki, H.; El Gharbi, R.; Fery-Forgues, S.; J. Heterocycl. Chem. 2009, 46, 28.

9. Pasco, M. Y.; Rotili, D.; Altucci, L.; Farina, F.; Rouleau, G. A.; Mai, A.; Néri, C.; J. Med. Chem. 2010, 53, 1407.

10. Kidwai, M.; Poddar, R.; Diwaniyan, S.; Kuhad, R. C.; Adv. Synth. Catal. 2009, 351, 589.

11. Khan, K. M.; Ali, M.; Ajaz, A.; Perveen, S.; Choudhary, M. I.; Atta-ur-Rahman; Lett. Drug Des. Discovery 2008, 5, 286.

12. Rotili, D.; Tarantino, D.; Carafa, V.; Lara, E.; Meade, S.; Botta, G.; Nebbioso, A.; Schemies, J.; Jung, M.; Kazantsev, A. G.; Esteller, M.; Fraga, M. F.; Altucci, L.; Mai, A.; ChemMedChem 2010, 5, 674.

13. Conrad, M.; Reinbach, H.; Ber. Dtsch. Chem. Ges. 1901, 34, 1339.

14. Pavolini, T.; Riv. Ital. Essenze Perfumi. 1933, 15, 171.

15. Ridi, M.; Aldo, G.; Gazz. Chim. Ital. 1952, 82, 13.

16. Figueroa-Villar, J. D.; Cruz, E. R.; Tetrahedron 1993, 49, 2855.

17. Figueroa-Villar, J. D.; Cruz, E. R.; Santos L. N.; Synth. Commun. 1992, 22, 1159.

18. Alcerreca, G.; Sanabria, R.; Miranda, R.; Arroyo, G.; Tamariz, J.; Delgado, F.; Synth. Commun. 2000, 30, 1295.

19. Li, J. T.; Sun, M. X.; Aust. J. Chem. 2009, 62, 353.

20. Zidar, N.; Kikelj, D.; Acta Chim. Slov. 2011, 58, 151.

21. Figueroa-Villar, J. D.; Carneiro, C. L.; Cruz, E. R.; Heterocycles 1992, 34, 891.

22. Figueroa-Villar, J. D.; Clemente, F. C.; Synth. Commun. 1998, $28,4325$.

23. Xu, Y. L.; Dolbier, W. R.; Tetrahedron 1998, 54, 6319.

24. Figueroa-Villar, J. D.; Clemente, F. C.; Silva, A. C. C.; J. Braz. Chem. Soc. 2001, 11, 247.

25. Jursic, B. S.; Stevens, E. D.; Tetrahedron Lett. 2003, 44, 2203.

26. Nimavat, K. S.; Popat, K. H.; Vasoya, S. L.; Joshi, H. S.; Indian J. Heterocycl. Chem. 2003, 12, 217.
27. Seeliger, F.; Berger, S. T. A.; Remennikov, G. Y.; Polborn, K.; Mayr, H.; J. Org. Chem. 2007, 72, 9170.

28. Vieira, A. A.; Gomes, N. M.; Matheus, M. E. ; Fernandes, P. D.; Figueroa-Villar, J. D.; J. Braz. Chem. Soc. 2011, 22, 364.

29. Varma, R. S., Green Chem. 1999, 43.

30. Martins, T. L. C.; Franca, T. C. C.; Ramalho, T. C.; FigueroaVillar, J. D.; Synth. Commun. 2004, 34, 3891.

31. Bougrin, K; Loupy, A; Soufiaoui, M.; J. Photochem. Photobiol., C 2005, 6, 139.

32. Martins, M. A. P.; Beck, P.; Machado, P.; Brondani, S.; Moura, S.; Zanatta, N.; Bonacorso, H. G.; Flores, A. F. C.; J. Braz. Chem. Soc. 2006, 17, 408.

33. Lenardão, E. J.; Silva, M. S.; Mendes, S. R.; de Azambuja, F.; Jacob, R. G.; dos Santos, P. C. S.; Perin, G.; J. Braz. Chem. Soc. 2007, 18, 943.

34. Buriol, L.; Frizzo, C. P.; Marzari, M. R. B.; Moreira, D. N.; Prola, L. D. T.; Zanatta, N.; Bonacorso, H. G.; Martins, M. A. P.; J. Braz. Chem. Soc. 2010, 21, 1037.

35. Barreto, A. F. S.; Vercillo, O. E.; Andrade, C. K. Z.; J. Braz. Chem. Soc. 2011, 22, 462.

36. Caddick S.; Tetrahedron 1995, 51, 10403.

37. Caddick, S.; Fitzmaurice, R.; Tetrahedron 2009, 65, 3325.

38. Kranjc, K.; Kocevar, M.; Curr. Org. Chem. 2010, 14, 1050.

39. Schmoger, C.; Stolle, A.; Bonrath, W.; Ondruschka, B.; Curr. Org. Chem. 2011, 15, 151.

40. Kruithof, A.; Ruijter, E.; Orru, R. V. A.; Curr. Org. Chem. 2011, 15, 204.

41. Dixit, N.; Goto, K.; Mishra, L.; Roesky, H. W.; Polyhedron 2010, 29, 1299

42. Pasco, M. Y.; Rotili, D.; Altucci, L.; Farina, F.; Rouleau, G. A.; Mai, A.; Neri, C.; J. Med. Chem. 2010, 53, 1407.

43. Rotili, D.; Tarantino, D.; Carafa, V.; Lara, E.; Meade, S.; Botta, G.; Nebbioso, A.; Schemies, J.; Jung, M.; Kazantsev, A. G.; Esteller, M.; Fraga, M. F.; Altucci, L.; Mai, A.; ChemMedChem 2010, 5, 674.

44. Ali, H. I.; Tomita, K.; Akaho, E.; Kambara, H.; Miura, S.; Hayakawa, H.; Ashida, N.; Kawashima, Y.; Yamagishi, T.; Ikeya, H.; Yoneda, F.; Nagamatsua, T.; Bioorg. Med. Chem. 2007, 15, 242.

45. Yoneda, F.; Hirayama, R.; Yamashita, M.; J. Heterocycl. Chem. 1982, 19, 301.
Submitted: April 27, 2011

Published online: September 6, 2011 


\section{Supplementary Information}

\section{Synthesis and Mechanism of Formation of Oxadeazaflavines by Microwave Thermal Cyclization of ortho-Halobenzylidene Barbiturates}

\section{J. Daniel Figueroa-Villar*,a and Sandra C. G. de Oliveira}

Grupo de Química Medicinal, Departamento de Química, Instituto Militar de Engenharia,

Praça General Tibúrcio 80, Praia Vermelha, 22290-270 Rio de Janeiro-RJ, Brazil

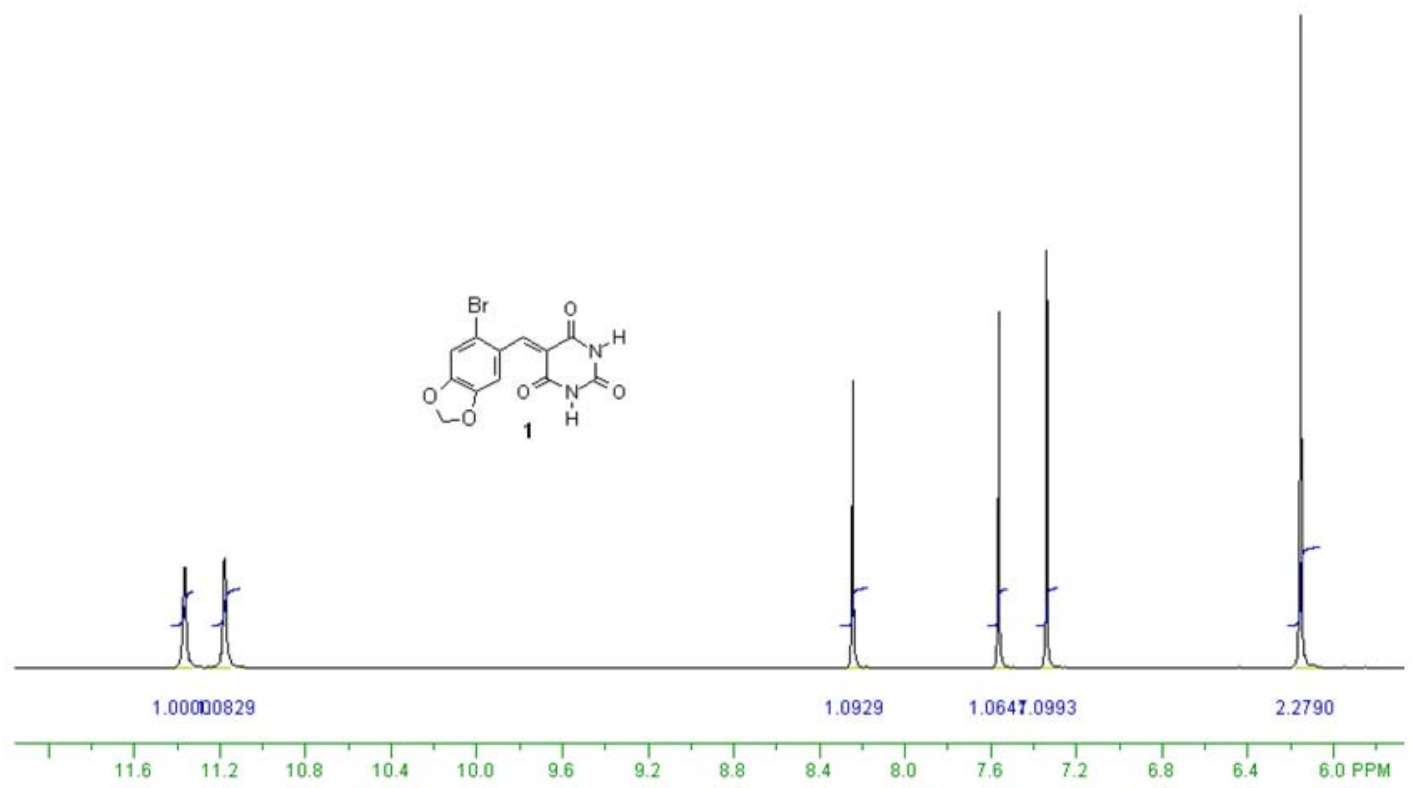

Figure S1. ${ }^{1} \mathrm{H}$ NMR spectrum (DMSO- $d_{6}, 300 \mathrm{MHz}$ ) of 6-bromopiperonylidene barbiturate (1). 


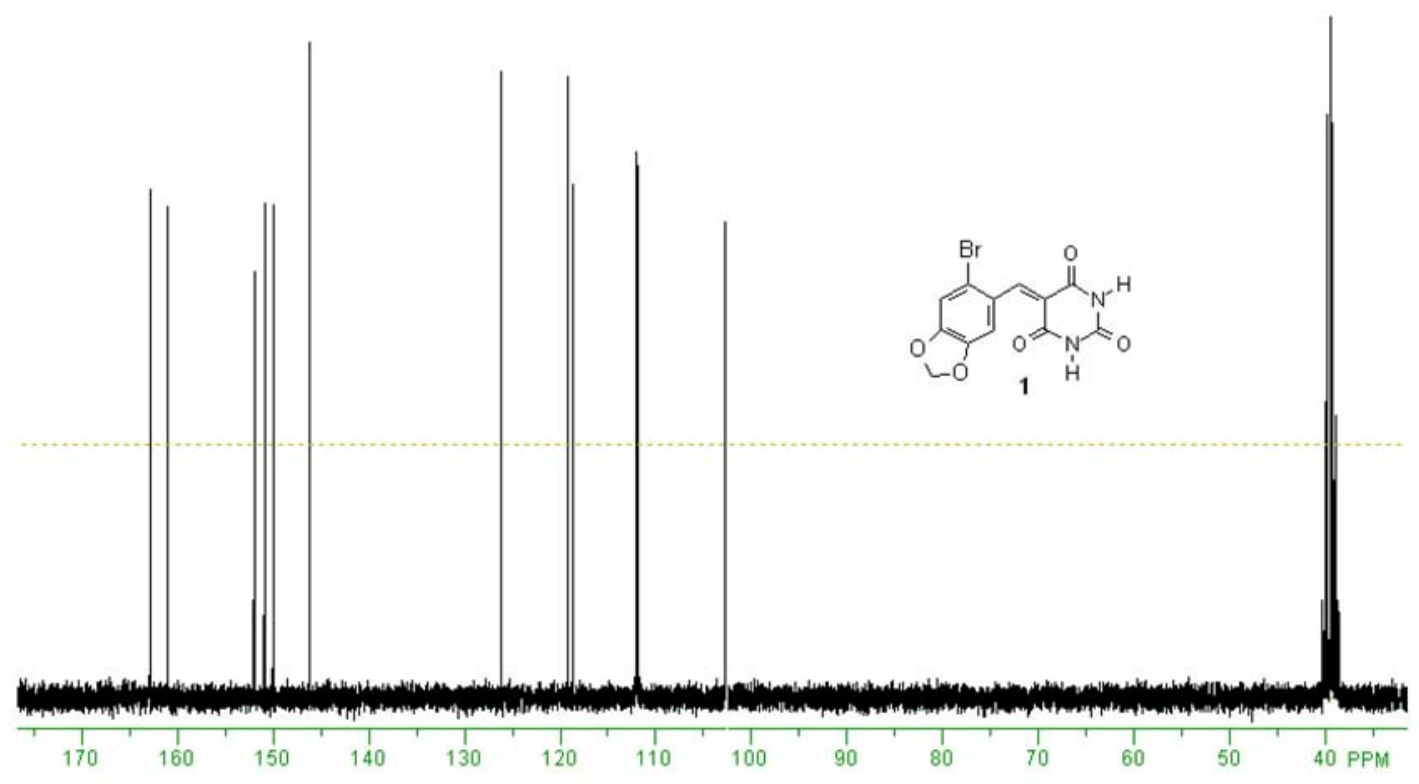

Figure S2. ${ }^{13} \mathrm{C}$ NMR spectrum (DMSO- $d_{6}, 75 \mathrm{MHz}$ ) of 6-bromopiperonylidene barbiturate (1).

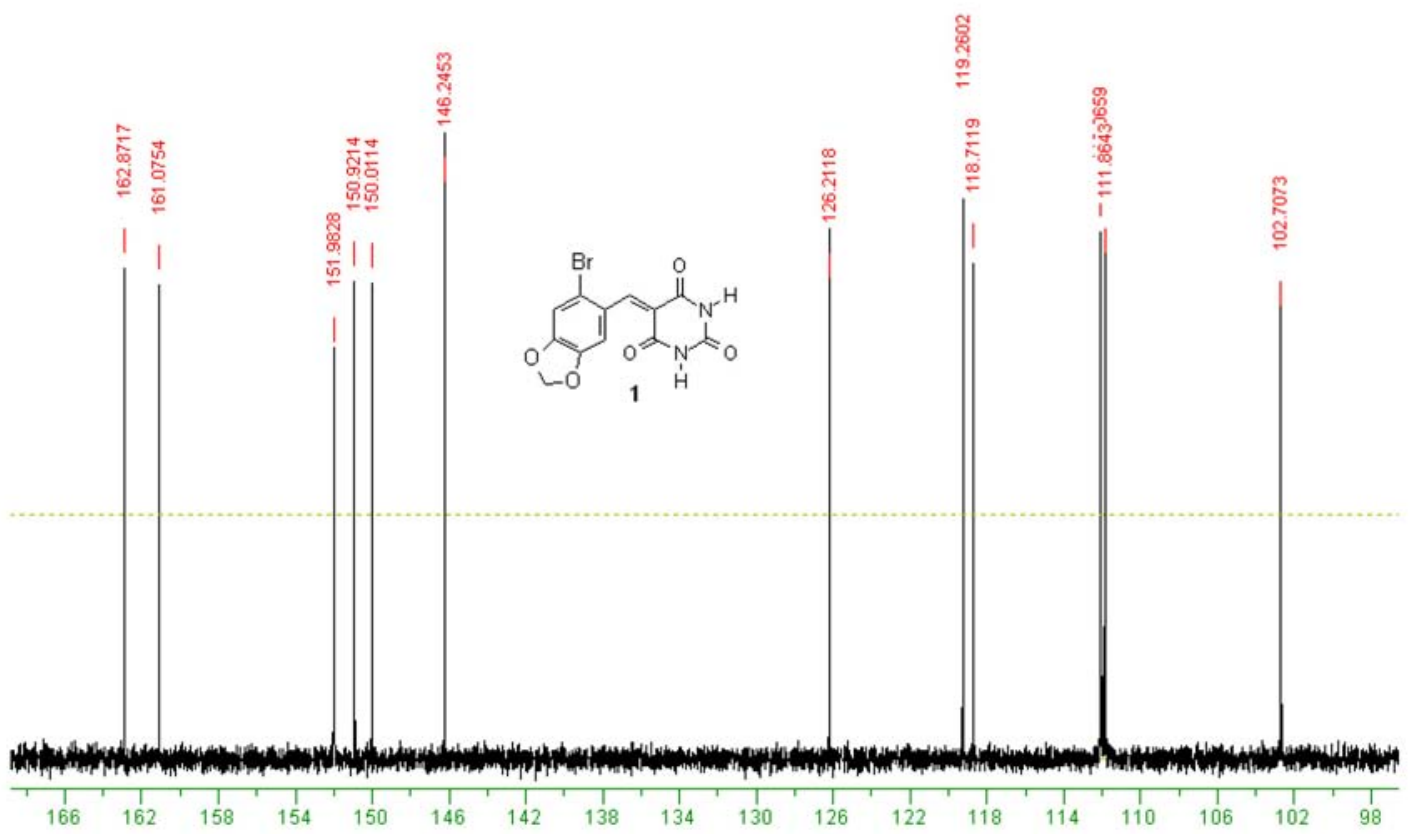

Figure S3. Expanded ${ }^{13} \mathrm{C}$ NMR spectrum of 6-bromopiperonylidene barbiturate (1). 


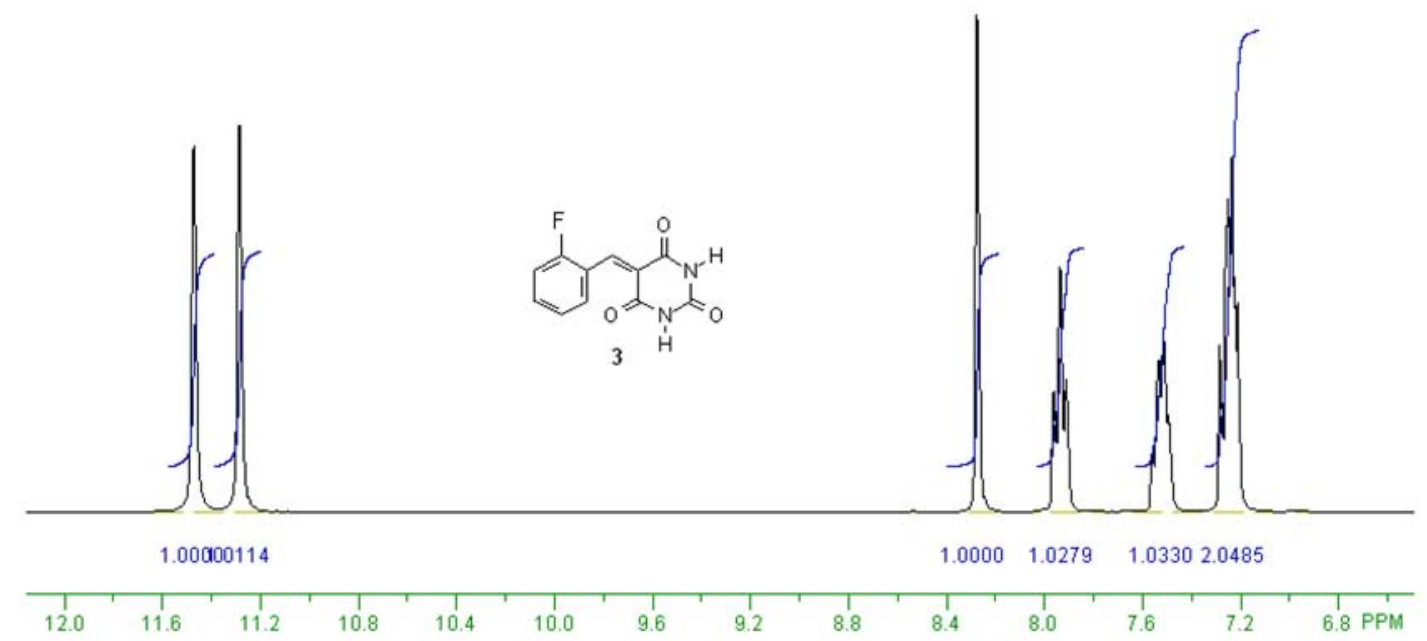

Figure S4. ${ }^{1} \mathrm{H}$ NMR spectrum (DMSO- $d_{6}, 300 \mathrm{MHz}$ ) of ortho-fluorobenzylidene barbiturate (3).
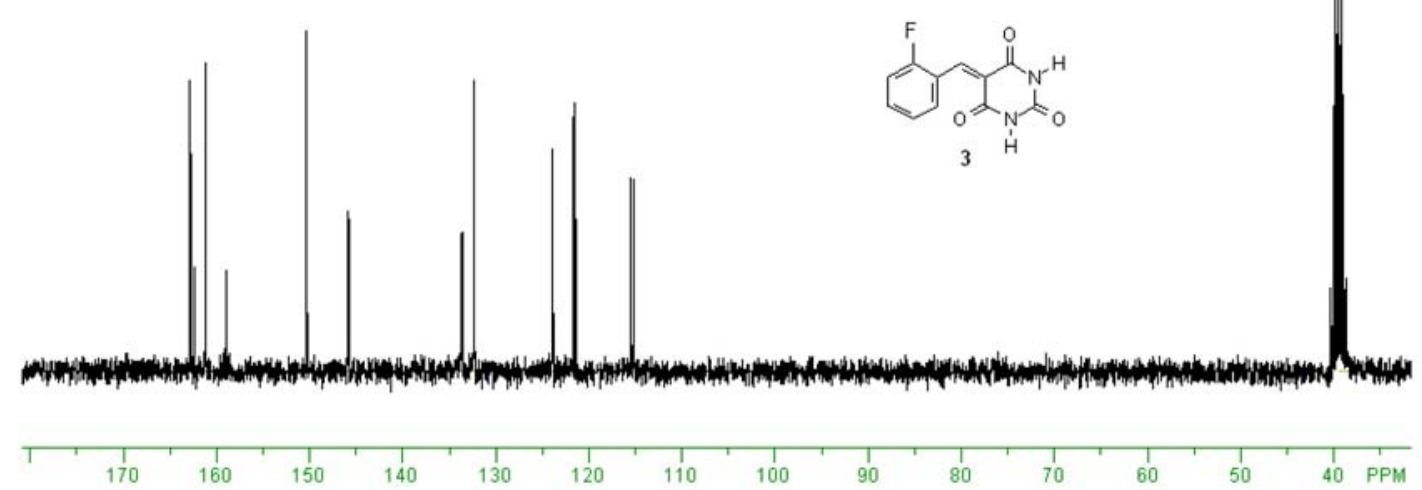

Figure S5. ${ }^{13} \mathrm{C}$ NMR spectrum (DMSO- $d_{6}, 300 \mathrm{MHz}$ ) of ortho-fluorobenzylidene barbiturate (3). 


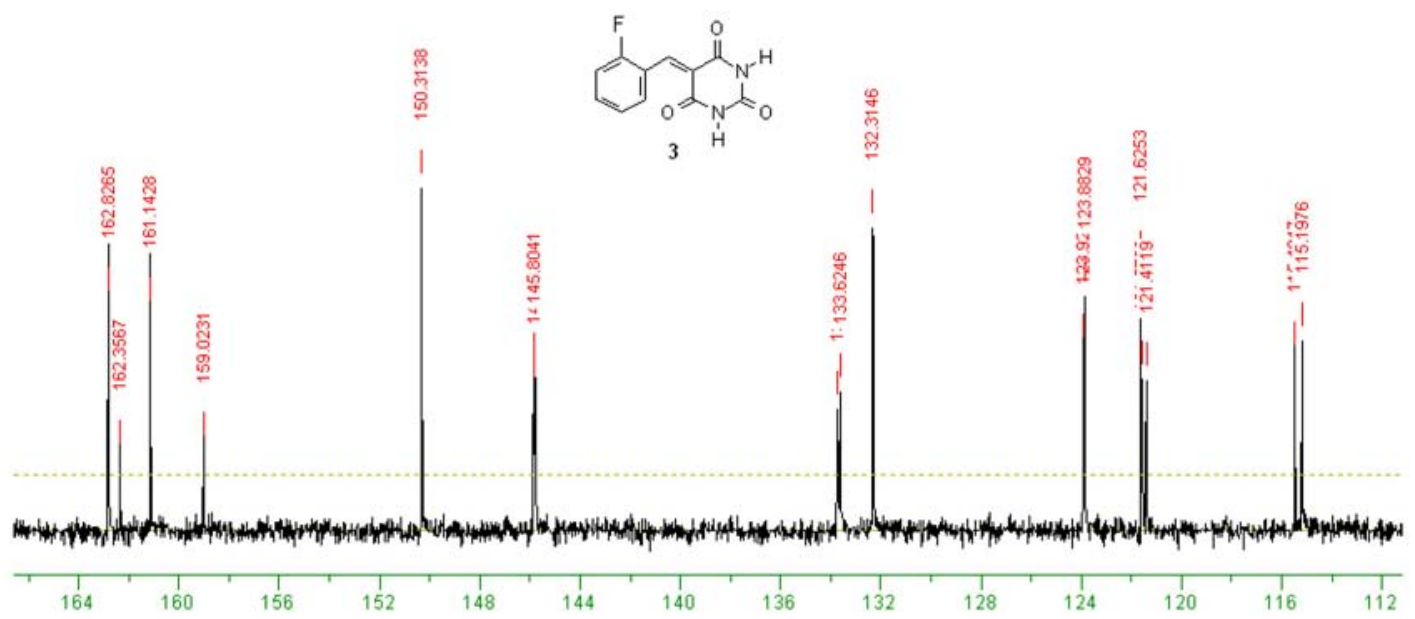

Figure S6. Expanded ${ }^{13} \mathrm{C}$ NMR spectrum of ortho-fluorobenzylidene barbiturate (3).

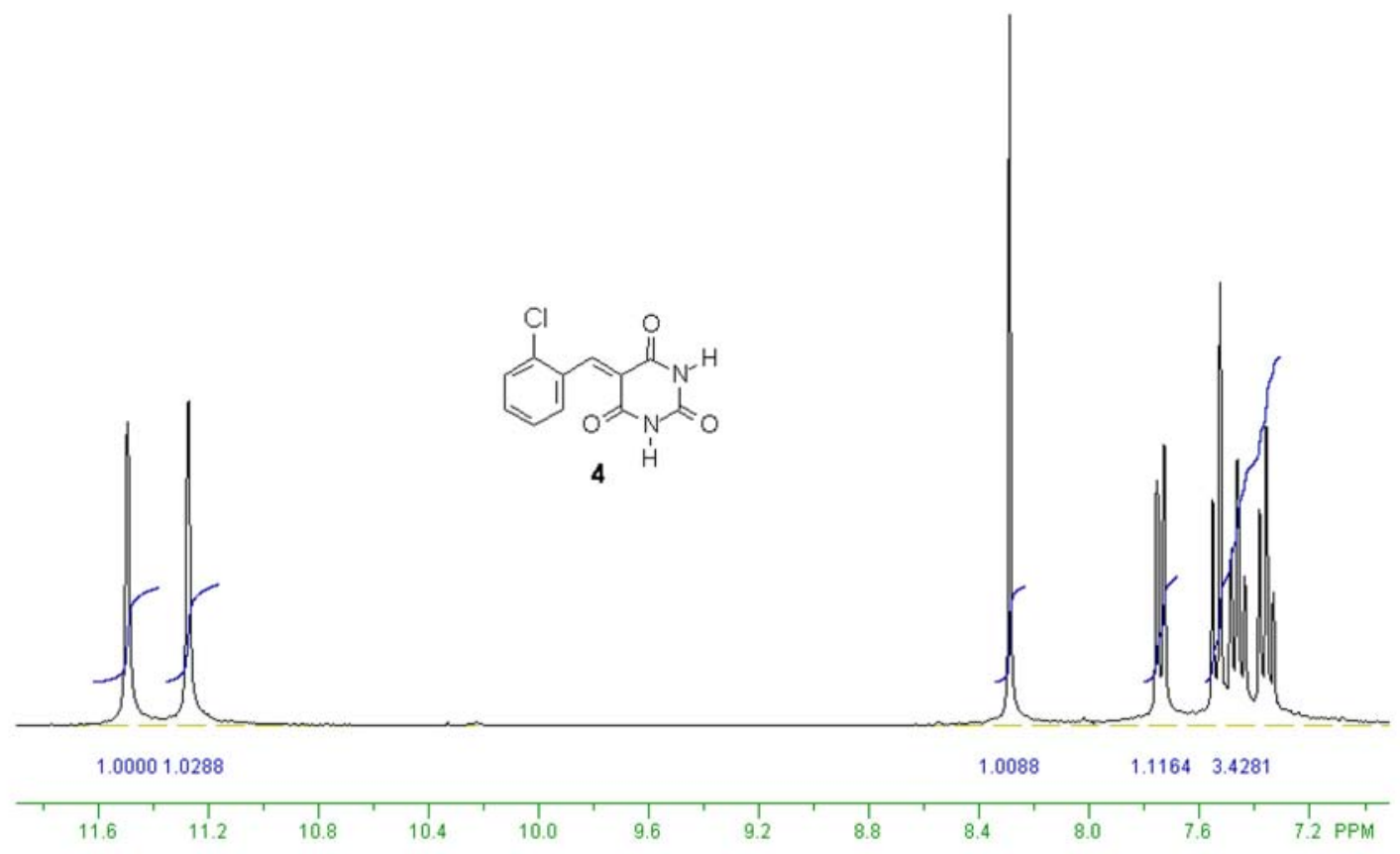

Figure S7. ${ }^{1} \mathrm{H}$ NMR spectrum (DMSO- $d_{6}, 300 \mathrm{MHz}$ ) of ortho-chlorobenzylidene barbiturate (4). 


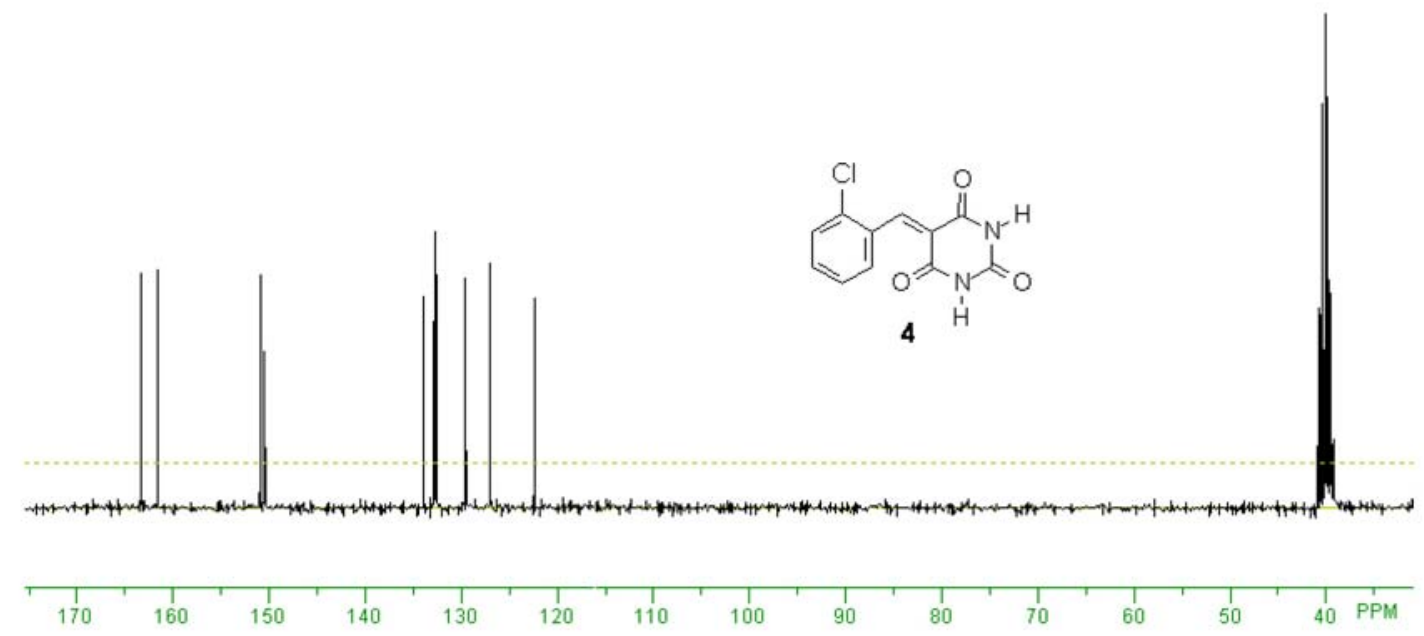

Figure S8. ${ }^{13} \mathrm{C}$ NMR spectrum (DMSO- $d_{6}, 300 \mathrm{MHz}$ ) of ortho-chlorobenzylidene barbiturate (4).

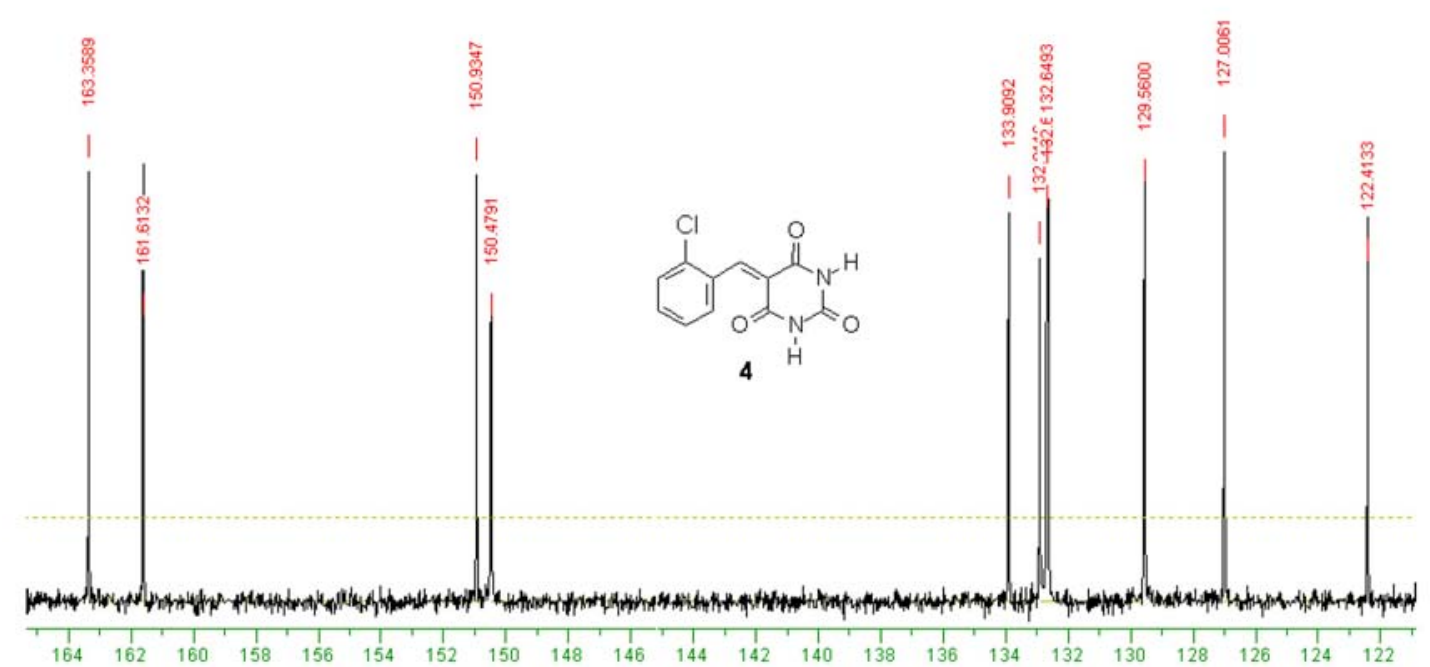

Figure S9. Expanded ${ }^{13} \mathrm{C}$ NMR spectrum of ortho-chlorobenzylidene barbiturate (4). 


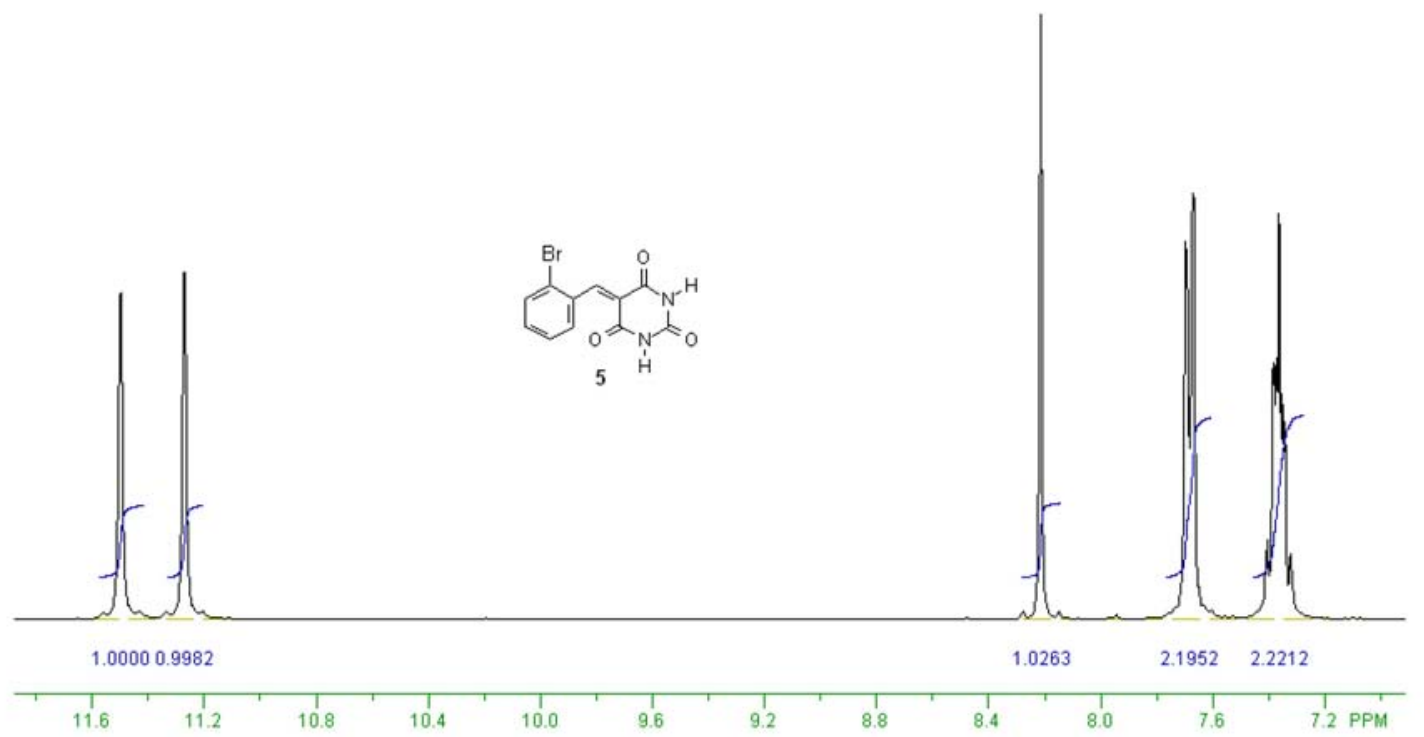

Figure S10. ${ }^{1} \mathrm{H}$ NMR spectrum (DMSO- $d_{6}, 300 \mathrm{MHz}$ ) of ortho-fluorobenzylidene barbiturate (5).

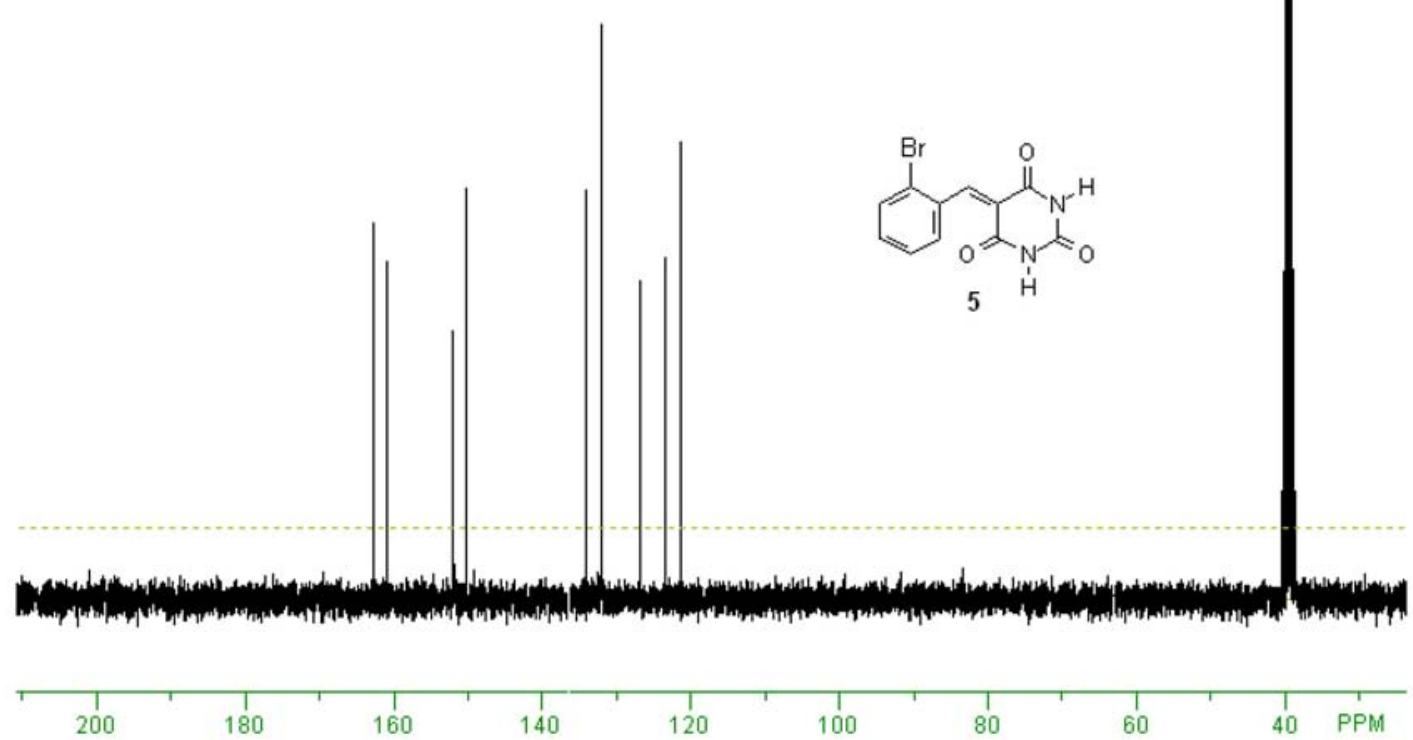

Figure S11. ${ }^{13} \mathrm{C}$ NMR spectrum (DMSO- $d_{6}, 300 \mathrm{MHz}$ ) of ortho-fluorobenzylidene barbiturate (5). 

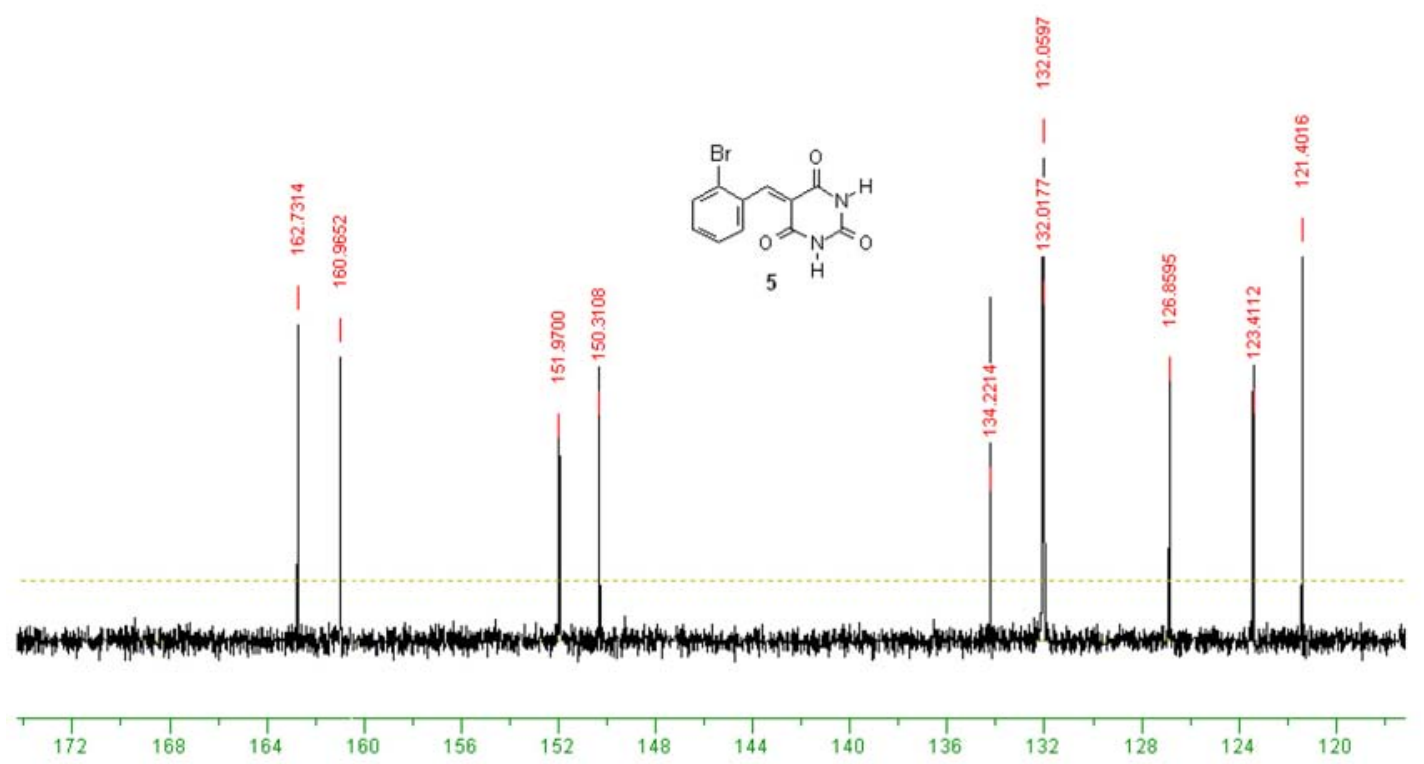

Figure S12. Expanded ${ }^{13} \mathrm{C}$ NMR spectrum of ortho-fluorobenzylidene barbiturate (5).

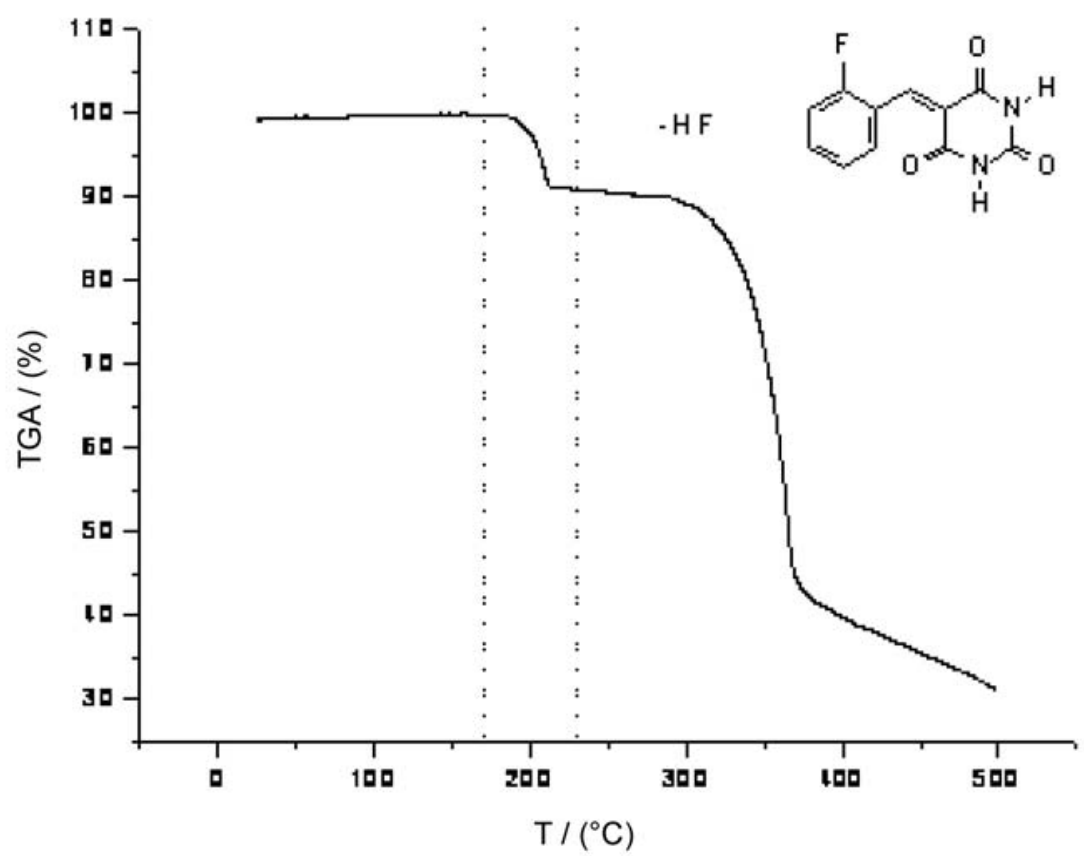

Figure S13. Thermogravimetric analysis (TGA) graphic of ortho-fluorobenzylidene barbiturate (3). 


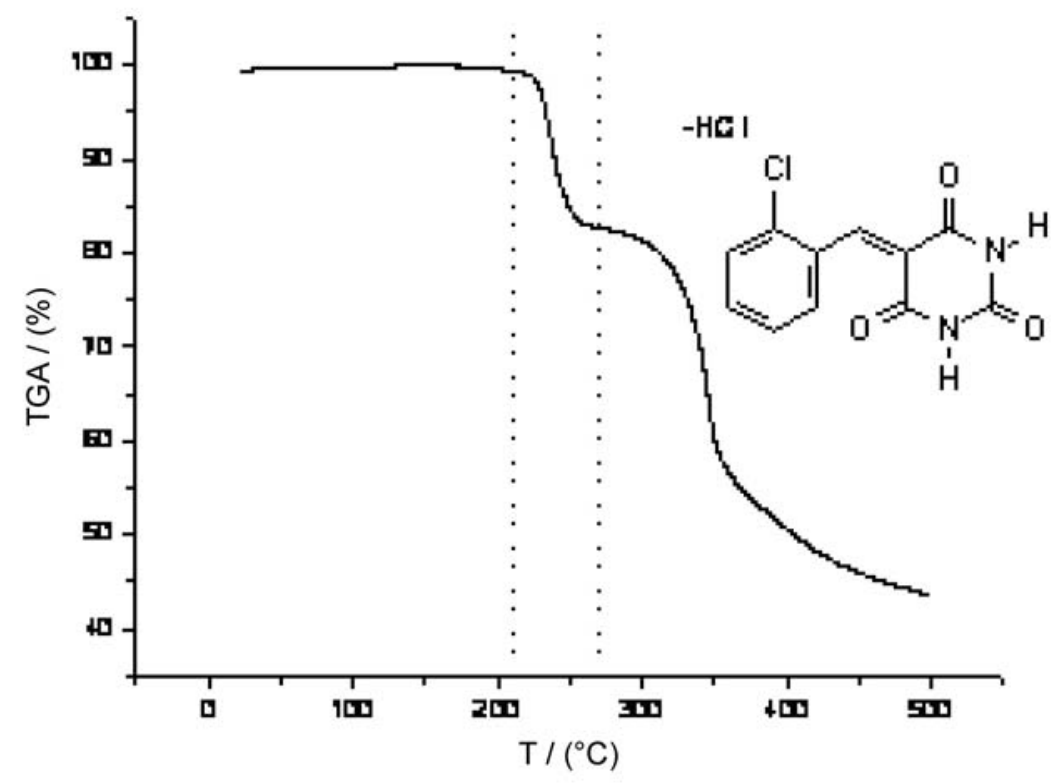

Figure S14. Thermogravimetric analysis (TGA) graphic of ortho-chlorobenzylidene barbiturate (4).

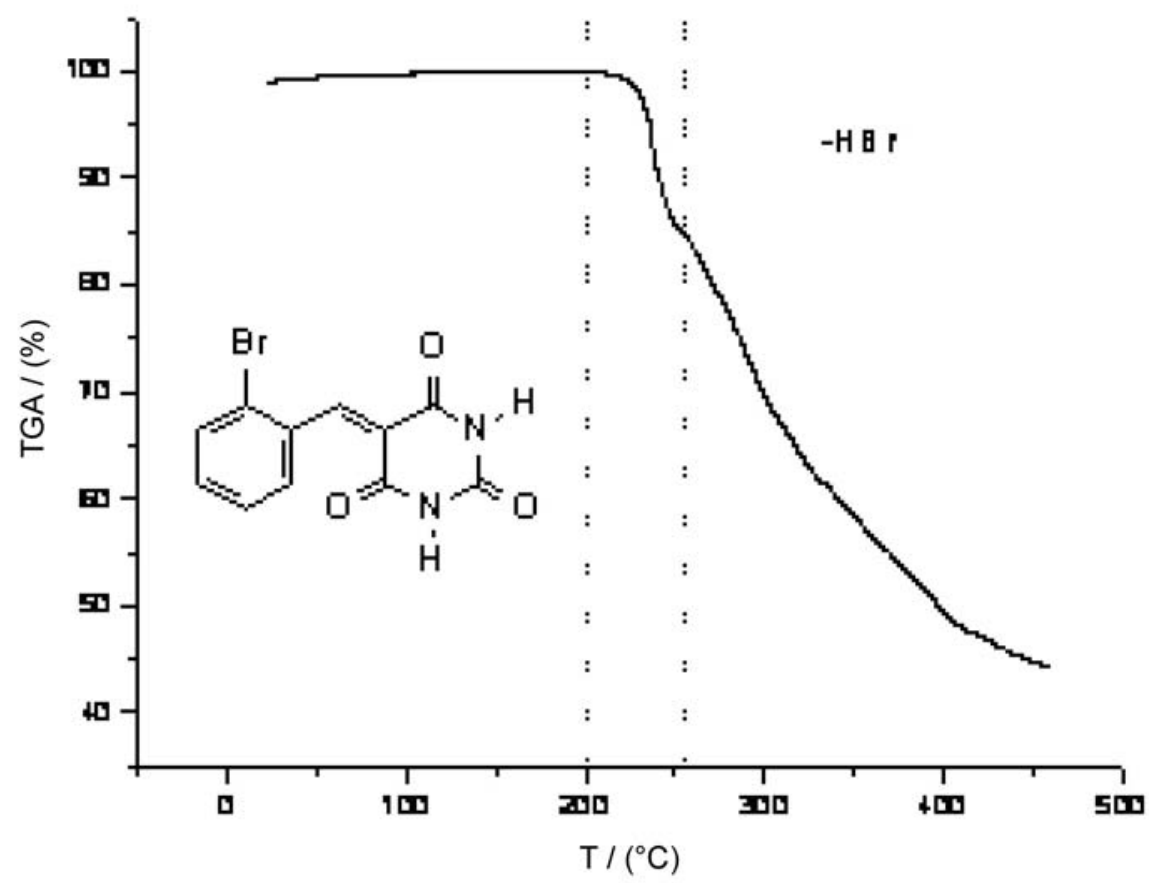

Figure S15. Thermogravimetric analysis (TGA) graphic of ortho-bromobenzylidene barbiturate (5). 


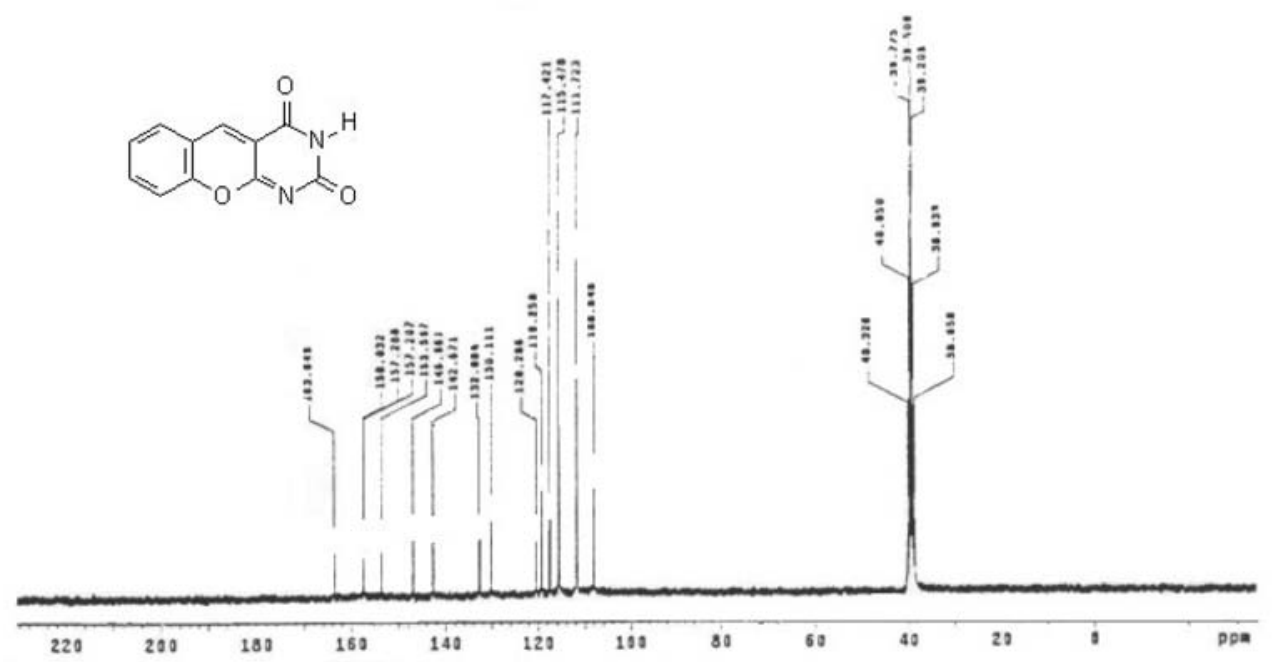

Figure S16. ${ }^{13} \mathrm{C}$ NMR spectrum (DMSO- $d_{6}, 75 \mathrm{MHz}$ ) of $2 \mathrm{H}$-chromeno[2,3-d]pyrimidine-2,4(3H)-dione (oxadeazaflavine).

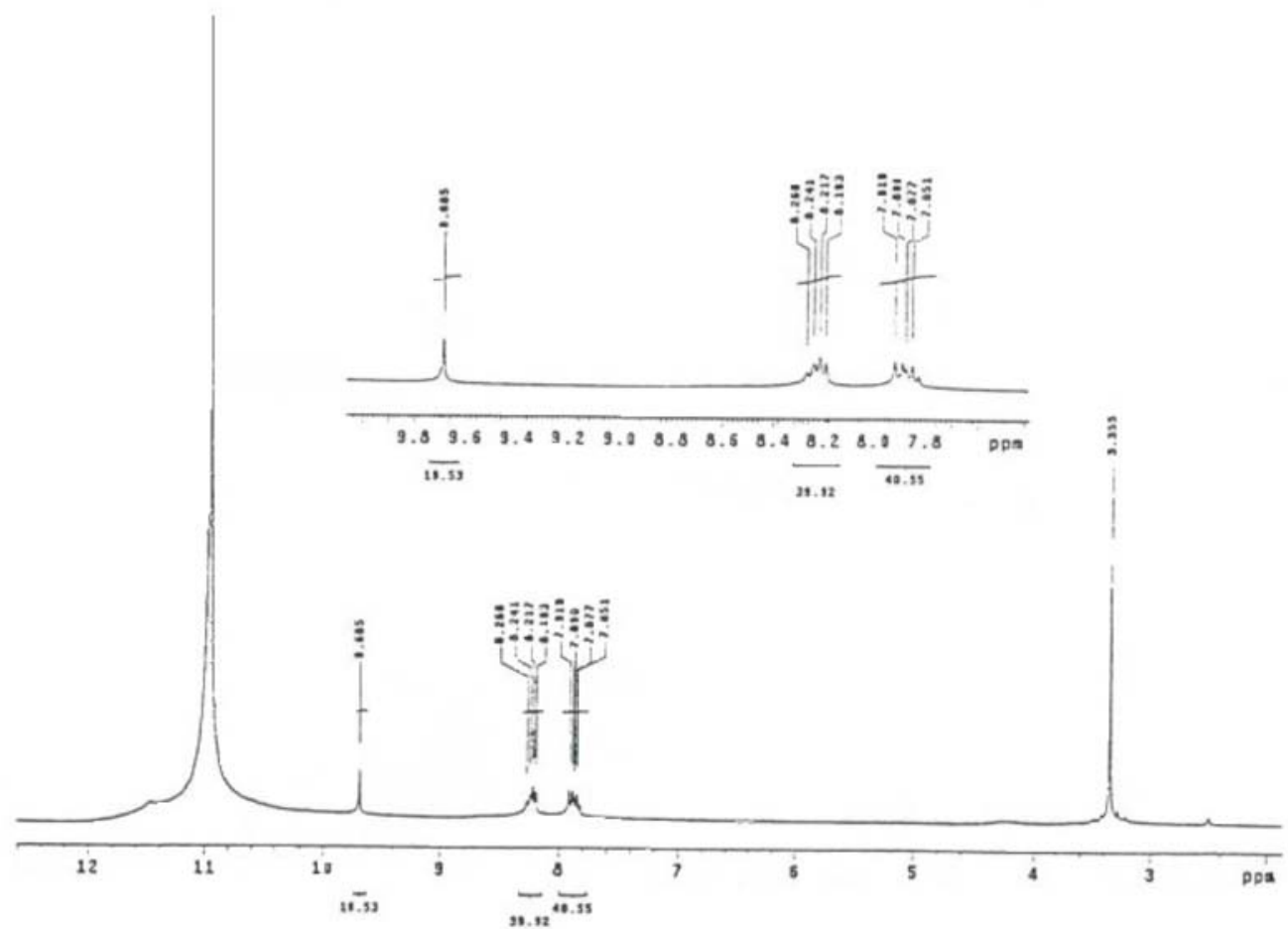

Figure S17. ${ }^{1} \mathrm{H}$ NMR spectrum (DMSO- $d_{6}, 300 \mathrm{MHz}$ ) of $2 \mathrm{H}$-chromeno[2,3-d]pyrimidine-2,4(3H)-dione (oxadeazaflavine). 


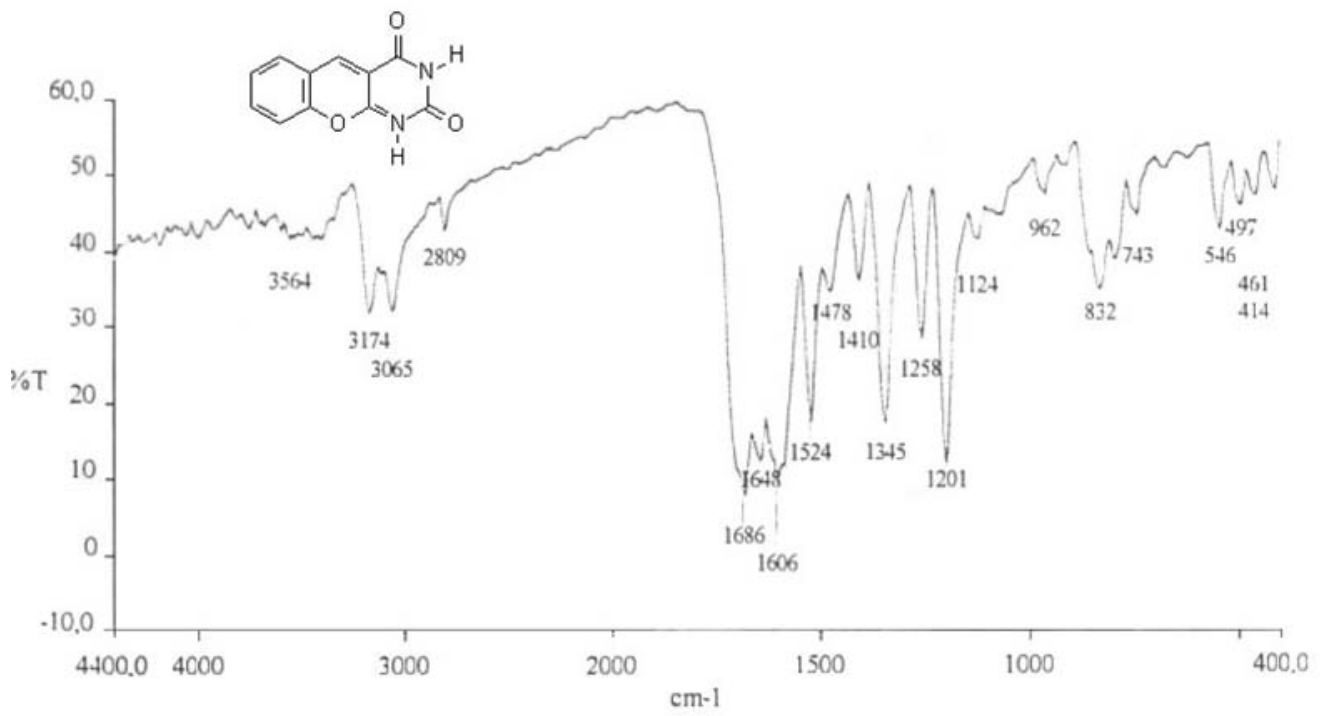

Figure S18. IR spectrum of 2H-chromeno[2,3-d]pyrimidine-2,4(3H)-dione (oxadeazaflavine).

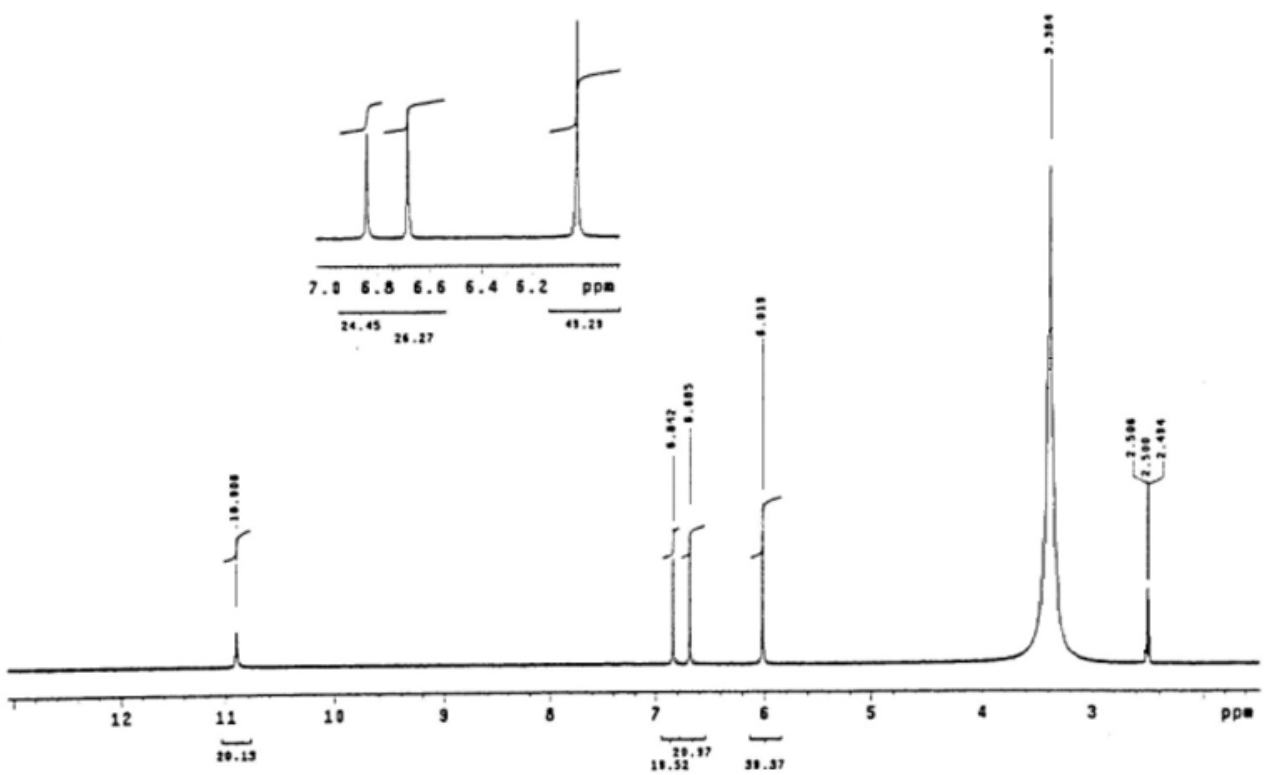

Figure S19. ${ }^{1} \mathrm{H}$ NMR spectrum (DMSO- $d_{6}, 300 \mathrm{MHz}$ ) of $2 \mathrm{H}-[1,3]$ dioxolo[4', $\left.5^{\prime}: 6,7\right]$ chromeno[2,3-d]pyrimidine-2,4(3H)-dione (2). 
<smiles>O=c1nc2oc3cc4c(cc3cc-2c(=O)[nH]1)OCO4</smiles>
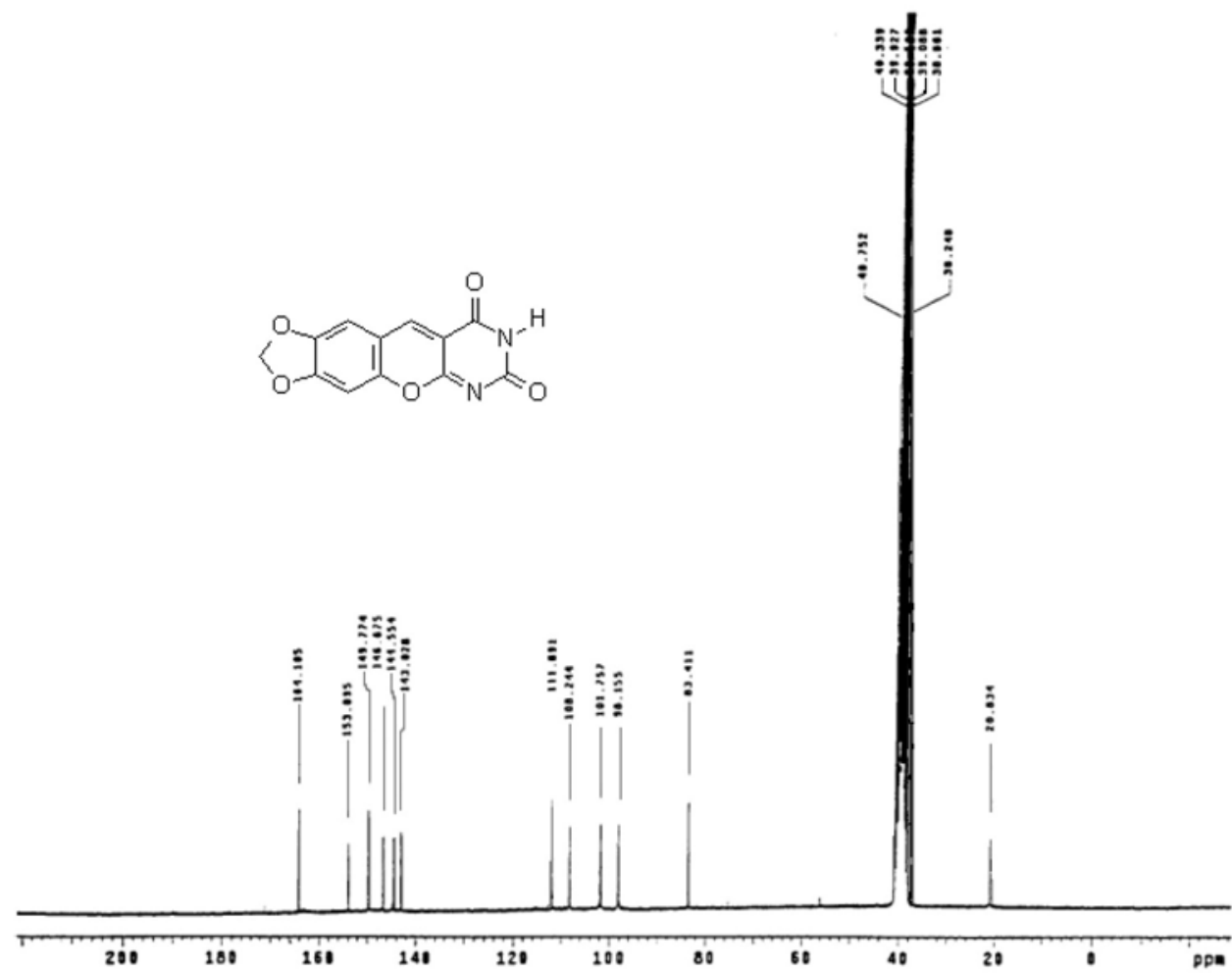

Figure S20. ${ }^{1} \mathrm{H}$ NMR spectrum (DMSO- $d_{6}, 300 \mathrm{MHz}$ ) of $2 \mathrm{H}-[1,3]$ dioxolo[4', 5':6,7]chromeno[2,3-d]pyrimidine-2,4(3H)-dione (2).

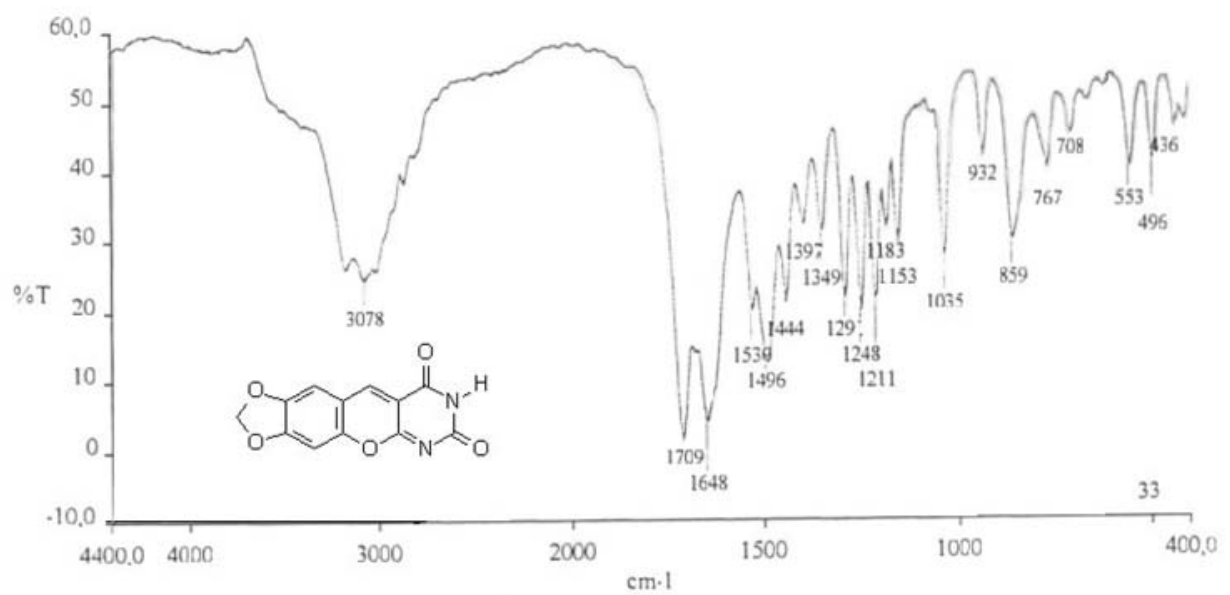

Figure S21. IR spectrum of 2H-[1,3]dioxolo[4',5':6,7]chromeno[2,3-d]pyrimidine-2,4(3H)-dione (2). 